This manuscript has been accepted for publication in Annual Review of Clinical Psychology. This version has not been copyedited, and therefore is not the version of record.

\title{
Real-Time fMRI in the Treatment of Mental Health Disorders
}

\author{
Vincent Taschereau-Dumouchel ${ }^{1,2, *}$, Cody Cushing ${ }^{3} \&$ Hakwan Lau ${ }^{4}$
}

\author{
Affiliations: \\ 1 - Department of Psychiatry and Addictology, University of Montreal, Montreal, Canada. \\ 2 - Centre de Recherche de l'Institut Universitaire en Santé Mentale de Montréal, Montreal, \\ Canada. \\ 3 - Department of Psychology, UCLA, Los Angeles, 90095, USA. \\ 4 - Center for Brain Science, Riken Institute, Japan
}

\section{Orcid:}

V.T-D.: https://orcid.org/0000-0002-9245-7934

C.C.: https://orcid.org/0000-0002-3877-3354

H.L.: http://orcid.org/0000-0001-8433-4232

Correspondence to: V.T-D. (vincenttaschereau@gmail.com)

Word count: $7486+300+(4 \times 600)=10,186$

Word limit: 10,200 


\begin{abstract}
Multiple mental disorders have been associated with dysregulations of precise brain processes. However, few therapeutic approaches are currently available in order to correct such specific patterns of brain activity. Since the late 60 s and early 70 s, many have hoped that this feat could be achieved by closed-loop brain imaging approaches, such as neurofeedback, that aim at modulating brain activity directly. However, neurofeedback never acquired mainstream acceptance in mental health, in part due to methodological considerations. Here, we argue that, when contemporary methodological guidelines are followed, neurofeedback is one of the few intervention methods in psychology that can be assessed in double-blind placebo-controlled trials. Furthermore, using new advances in machine learning and statistics, it is now possible to target very precise patterns of brain activity for therapeutic purposes. We review the recent literature in functional magnetic resonance imaging (fMRI) neurofeedback and discuss current and future applications to mental health.
\end{abstract}

Keywords: Real-time brain imaging, machine learning, neurofeedback, decoded neurofeedback, functional magnetic resonance imaging. 


\section{Introduction}

The treatment of mental illnesses still represents one of the greatest contemporary challenges. During the 20th century, considerable scientific efforts were devoted to developing new intervention methods in mental health. However, many treatment strategies turned out to be less successful than expected (Hyman, 2012; Griebel and Holmes, 2013). For instance, after years of research, pharmaceutical companies are now reducing their efforts to develop new treatments for many mental disorders (Miller, 2010; Hyman, 2012; Greenberg, 2013). This state of affairs urges researchers and clinicians to rethink classical intervention methods through the lens of new concepts and modern technologies.

In recent years, modern machine learning algorithms achieved remarkable successes in the field of pattern recognition and computer vision (LeCun, Bengio and Hinton, 2015;

Goodfellow et al., 2016). Such algorithms (sometimes called decoders) have notably been applied to recognize patterns of brain activity associated with specific psychological states (Haxby et al., 2001; Haxby, Connolly and Guntupalli, 2014; Cohen et al., 2017). For instance, such brain decoders have been used to predict the subjective experience of fear (Taschereau-Dumouchel, Kawato and Lau, 2020; Zhou et al., 2020) or pain (Wager et al., 2013; Woo et al., 2017). Thanks to the increasing power of computation hardware and the sophistication of modern neuroimaging tools, it is now possible to conduct such brain decoding in real time. This new reality opens up interesting avenues for the purpose of clinical intervention (Keynan et al., 2016, 2019; Ramot et al., 2017; Taschereau-Dumouchel, Liu and Lau, 2018). For instance, this technology can be used to devise various clinical interventions aiming at modulating brain activity. This can notably be achieved by providing participants with visual or auditory feedback representing their decoded brain activity (i.e., neurofeedback intervention). Such interventions can be designed in order to facilitate the reinforcement of brain activity directly and unconsciously in the human brain (Taschereau-Dumouchel, Liu and Lau, 
2018). Importantly, as we will see, the efficacy of such closed-loop interventions can be rigorously assessed in double-blind placebo-controlled experiments.

As numerous reviews of the fMRI neurofeedback literature have been written in recent years (Weiskopf, 2012; Sulzer et al., 2013; Sitaram et al., 2017; Watanabe et al., 2017; Thibault et al., 2018; Pindi et al., 2021), our goal is not to provide an extensive review of current literature. Rather, here we try to present an integrated historical overview of the field, with a particular focus on the road ahead. Specifically, we aim to discuss how modern statistical and experimental approaches are currently revitalizing the field of real-time brain imaging.

\section{A brief history of neurofeedback}

\section{a. Early closed-loop experiments}

Non-invasive brain imaging methods are correlational in nature. Using these approaches, we can observe an association between a given brain activity and an outcome. However, we usually do not know if a direct manipulation of the brain activity would also change the outcome. In the late 1960s-early 1970s, researchers devised some of the first closed-loop systems (Fig. 1) precisely to investigate the causality of brain activity. One such early experiment was conducted in 1969 by Eberhard Fetz. Fetz was interested in studying how precentral neurons generate muscle contractions in macaque monkeys. He showed that, by providing a food pallet contingent on the firing rate of precentral neurons, it was possible to increase the firing rate of these neurons by 50 to 500 percent (Fetz, 1969). Later on, Fetz and Finocchio used a similar approach in order to study the causal link between precentral neurons and peripheral muscle contractions. They showed that precentral neurons could be conditioned with or without simultaneously triggering peripheral contractions (Fetz and Finocchio, 1971). Taken together these early findings represented one of the first demonstrations that neural activity could be directly regulated in the brain, possibly through reinforcement learning. 
Furthermore, these findings called into question the direct causal influence of individual precentral neurons in muscle contraction and were taken as an early indicator of distributed coding in the brain.

Around the same time, other researchers were experimenting with electroencephalography (EEG). Here again, some early closed-loop experiments were designed in order to investigate the causality of specific brain signals. For instance, Joseph Kamiya was interested in studying the link between subjective experience and the alpha rhythm recorded in EEG signals (Kamiya, 1968, 2011). In a series of experiments, he reported that, when prompted by a bell, participants could learn to correctly guess if an alpha burst was occurring in their brain. While conducting such experiments, Kamiya noticed that participants could also learn to produce alpha bursts at will (Kamiya, 1962). This serendipitous finding prompted a follow-up experiment revealing that participants could indeed be trained to modulate their own alpha activity (Kamiya, 1966). Motivated by such early demonstrations, multiple new experiments were conducted and showed similar modulation of various brain signals (Sterman, Howe and Macdonald, 1970; Beatty et al., 1974).

\section{b. Early fMRI experiments}

Years later, the first functional MRI experiments were reported (Kwong et al., 1992; Ogawa et al., 1992), and soon, it was shown that functional brain images could be processed in real time (Cox, Jesmanowicz and Hyde, 1995). This demonstration prompted many efforts to develop tools allowing one to conduct pre-processing steps and statistical analyses in real time (Goddard et al., 1997; Cox and Jesmanowicz, 1999; Voyvodic, 1999; Gembris et al., 2000; Cohen, 2001; Mathiak and Posse, 2001; Posse et al., 2001; Smyser et al., 2001; Bagarinao et al., 2003). These tools paved the way for the first fMRI neurofeedback experiments (Yoo and Jolesz, 2002; Posse et al., 2003; Weiskopf et al., 2003; Weiskopf, Mathiak, et al., 2004; 
Weiskopf, Scharnowski, et al., 2004; Weiskopf, 2012). In such experiments, participants were commonly trained to continuously modulate their brain activity during experimental blocks lasting from a few seconds to approximately a minute. Using this approach, early experiments showed successful modulation of brain activity in regions such as M1/S1 (Yoo and Jolesz, 2002; Yoo et al., 2004), the amygdala (Posse et al., 2003), anterior cingulate cortex, the supplementary motor area and the parahippocampal place area (Weiskopf et al., 2003; Weiskopf, Mathiak, et al., 2004). These findings prompted a great interest to explore potential therapeutic applications and to better understand underlying principles of neurofeedback.

\section{Recent advances in real-time fMRI}

Since these early fMRI studies, many methodological advances have been achieved (Watanabe et al., 2017). Thanks to the recent explosion of research in artificial intelligence and machine learning (LeCun, Bengio and Hinton, 2015) and to the ever increasing power of modern computers (Moore, 2021), there is now considerable momentum for the development of novel and improved neurofeedback methods. In the last few years, a vast repertoire of analytical approaches have been developed for the purpose of real-time brain modulation. In the next sections, we will detail some of these recent advances and pay special attention to developments with potential clinical applications.

\section{a. Decoded fMRI Neurofeedback}

In neurofeedback, one persistent challenge is to determine the relevant brain activity to target. This represents a challenge because brain regions are not associated with a unique function. Without explicitly delineating the relationship between brain signal and psychological states, one is at risk of training participants to activate irrelevant brain representations. Decoded neurofeedback aims specifically at addressing this problem using modern machine learning (or 
decoding) approaches. Decoded neurofeedback interventions typically involve conducting a first session, called the decoder construction session, where a multivariate decoder is trained to predict the occurrence of a specific psychological state from brain activity. For instance, such decoders have been trained with the brain representation of visual stimuli (Shibata et al., 2011; Amano et al., 2016; Koizumi et al., 2016) or finger movements (LaConte, Peltier and Hu, 2007; Oblak, Sulzer and Lewis-Peacock, 2019). Importantly, the unbiased accuracy of such decoders can be determined using current recommendations in the machine learning literature (Varoquaux, 2018). This can give us confidence in the association between the decoder output and the targeted psychological trait. Once an accurate decoder is trained, it is possible to target this representation in a closed-loop manner (see Fig. 2a). Multiple decoded neurofeedback experiments have now been conducted using this approach and highly specific neural and behavioral effects have been reported (for a review see, (Watanabe et al., 2017)). While decoded fMRI neurofeedback has not yet been used exhaustively with clinical populations, many experiments showed promising applications. These are detailed in the section: "Promising approaches in the treatment of mental disorders".

In the context of clinical interventions, constructing meaningful decoders may however represent a challenge. For instance, one might wish to train a decoder of a specific brain state without having to put a patient in a particularly dreadful situation (Taschereau-Dumouchel et al., 2018). Furthermore, one may want to train a brain decoder even when only a small amount of data can be collected for each participant. In these situations, between-subject decoders can be considered. However, between-subject decoders can also be challenging to train as they require the brain data of different participants to be represented in a common space. One possibility is to perform a structural alignment in a standard space, such as the MNI space (Fonov et al., 2009). This is routinely achieved in offline analyses. However, structural alignment is an extra pre-processing step that can slow down the processing of brain images in real time. Even if data 
from the $\mathrm{mNI}$ space are projected in the native space of the participant, the performance of decoders trained with structurally aligned data have been shown to be sometimes suboptimal (Haxby et al., 2011).

An interesting alternative is offered by functional alignment methods (Haxby et al., 2011; Chen et al., 2015). This family of approaches aims at aligning brain data coming from different participants using their functional profile. More precisely, these approaches aim at leveraging the response profile of the voxels (obtained in a "calibration" session) in order to perform the between-subject alignment. One advantage of such approaches is that they allow for the data of a group of participants to be represented in the native space of a given participant (see Fig. 2b). This property presents an interesting advantage for real-time interventions as the decoders can be trained in the native space. We previously showed that this approach can be successfully used in a closed-loop experiment (Taschereau-Dumouchel et al., 2018).

\section{b. Decoding EEG fingerprints}

EEG is probably the imaging modality most frequently used in order to conduct closed-loop interventions. Here also, machine learning approaches have been successfully used (Bu et al., 2019). However, EEG presents some limitations, such as a limited spatial resolution (Srinivasan et al., 1996). In order to improve the accuracy of EEG interventions, an interesting approach has been to combine EEG with fMRI. Previous work laid down solid foundations for the use of "EEG fingerprints" in neurofeedback (Keynan et al., 2016, 2019). This practice involves training a decoder of EEG activity to predict concurrent fMRI signals (see Fig. 3a). This can be achieved by acquiring $\mathrm{FMRI}$ and EEG signals simultaneously. Using this approach, it is possible to train a decoder of the EEG fingerprint that can later be used outside of the scanner for neurofeedback purposes. For instance,successful neurofeedback experiments have been conducted using a decoder of the EEG fingerprint of amygdala activity 
(Keynan et al., 2016, 2019). Importantly, approaches leveraging EEG fingerprints present multiple potential clinical applications (Keynan et al., 2019). For instance, one might consider targeting the EEG fingerprint of any decoded fMRI activity (see Fig. 3a). Accordingly, it might also be possible to target decoded fMRI activity using EEG neurofeedback.

\section{c. Connectivity-based neurofeedback}

Brain connectivity analyses gained considerable popularity in recent years (Bassett and Sporns, 2017; Avena-Koenigsberger, Misic and Sporns, 2018). This family of analyses was very successful in establishing links between inter-regional brain connectivity and mental disorders (Whitfield-Gabrieli and Ford, 2012). As a result, closed loop interventions have been designed in order to normalize the connectivity between specific brain regions in hope of also normalizing symptoms. These approaches can be termed connectivity-based neurofeedback. In these studies, the connectivity between two targeted regions is typically computed in real time and used in order to provide feedback to participants (see Fig. 3b). Multiple studies reported that inter-regional brain connectivity could indeed be successfully manipulated using multiple connectivity metrics such as correlational approaches (Megumi et al., 2015; Yamashita et al., 2017), sliding-window analysis (Gembris et al., 2000), the two-point approach (Ramot et al., 2017; Ramot and Gonzalez-Castillo, 2019), dynamic causal modeling (Koush et al., 2013; Koush, Meskaldji, et al., 2017) and tensor independent component analysis (Koush et al., 2019). Importantly, connectivity neurofeedback has been associated with some outcomes relevant to mental health (Ramot et al., 2017). This will be discussed further in the section: "Promising approaches in the treatment of mental disorders". 


\section{d. Information transmission analysis}

When conducting neurofeedback experiments, researchers are often interested in identifying brain processes involved in the modulation of brain activity. This question can be addressed using an information transmission analysis. This analysis aims at determining if the target of the intervention (e.g., decoded brain activity or regional activity) can be accurately predicted by the activity within other brain regions. Such analyses are often conducted within a searchlight procedure covering the whole brain or within specific regions of interest. In the context of decoded neurofeedback, an information transmission analysis can be seen as a form of multivariate connectivity metric indicating how much a given brain region can predict the occurrence of a multivariate representation elsewhere in the brain. This is an interesting metric that could potentially be used in the future as a target of neurofeedback. For instance, this could be used in order to train a brain region to increase or decrease the expression of a given decoder in another brain region.

\section{e. Co-adaptive systems}

Neurofeedback aims at modulating brain activity, possibly through physiological and psychological mechanisms involved in reinforcement learning (see the section: Investigating the mechanisms of action). However, this mechanism of action is not the only one capable of driving brain activity in real time. Many other means of interacting with individuals may also facilitate the expression of specific patterns of activity in their brains. Interestingly, it might be possible to optimize the expression of specific patterns of brain activity using modern artificial intelligence algorithms (Taschereau-Dumouchel and Roy, 2020). For instance, Zhang and colleagues trained a reinforcement learning algorithm to reduce the pain-related brain activity of users (Zhang et al., 2020). They first trained a pain decoder and obtained predicted pain ratings in real time while participants were receiving electrical stimulations. They fed this information in real 
time to a reinforcement learning algorithm (Fig. 4a). They showed that, after only a few trials, the algorithm learned which of two possible interventions (High-intensity or low-intensity electrical stimulations) could be delivered in order to reduce pain-related brain activity. These results are important as they illustrate the possibility of using artificial intelligence algorithms to devise means of interacting with the brain of users and to facilitate the expression of specific patterns of brain activity. One might envision a similar approach adapted to brain stimulation (either non-invasive or deep brain stimulation). In this scenario, diverse patterns of brain stimulation could be iterated over in order to optimize the expression of specific patterns of brain activity.

Yet another possibility is to leverage deep generative models in order to generate stimuli to be presented to participants in real time (Fig. 4b). This possibility was previously investigated by generating visual stimuli in order to optimise the firing rate of specific neurons in the visual system (Bashivan, Kar and DiCarlo, 2019; Ponce et al., 2019). These experiments, conducted in macaque monkeys, led to two important conclusions. First, such artificially created stimuli can greatly increase the firing rate of specific neurons, even beyond what is expected of natural stimuli. Second, such artificially created stimuli typically depict abstract shapes that do not represent any specific objects or animals. This suggests that artificially-generated stimuli could be used in order to facilitate the expression of specific brain signals in humans without divulging the nature of the targeted brain activity. This is an interesting feature as it would still allow one to conduct double-blind placebo-controlled experiments. As such, these findings are important as they suggest that artificially-generated stimuli might ultimately be used in order to support or complement neurofeedback interventions in mental health.

\section{f. Cloud computing and parallel processing}

The real-time processing of standard fMRI neurofeedback experiments can be easily achieved on most desktop computers. However, the speed of modern internet connections 
makes it possible to transfer fMRI data to a remote computer (i.e., in the cloud) in order to conduct processing over there in real time (Cohen et al., 2017; Mennen et al., 2021). This allows one to conduct more intensive analyses in real time while using relatively simple desktop computers onsite. This possibility is particularly interesting when combined with parallel computing as it can considerably speed up the analysis of fMRI data (Eklund et al., 2014). The idea of using parallel processing in real time is not new (Goddard et al., 1997), but it is now simpler to include such analyses in real time processing pipelines. This was made possible with the increasing power of graphics processing units (GPUs) and the development of open-source softwares leveraging GPU capabilities (Eklund et al., 2014). Importantly, parallel processing can considerably fasten preprocessing (Eklund et al., 2014) and first-level analyses (Eklund et al., 2014) and can also be used in order to run feature selection (Wang et al., 2016). Such technologies open up multiple opportunities to conduct complex analyses in real time. This was notably shown in a recent proof-of-concept study (Mennen et al., 2021).

\section{Investigating the mechanisms of action}

Based on experiments conducted with intracranial recording in animals, we have good reasons to believe that neurofeedback can indeed modulate precise patterns of neural activity (Fetz, 1969; Fetz and Finocchio, 1971; Sadtler et al., 2014). However, fMRI is quite different from intracranial recordings. Notably, it is conducted at the voxel level, not at the neuronal level. This is an important distinction as the haemodynamic signal may or may not reflect the underlying neural activity (Sirotin and Das, 2009). Moreover, at the voxel level, the signal can represent the activation of many different neurons within that voxel. Further, considering the number of voxels recorded in the brain, one might wonder how is it possible for participants to target such precise neural representations? To answer these questions, Shibata and colleagues proposed the targeted neuroplasticity hypothesis (Shibata et al., 2019). This hypothesis 
proposes that $\mathrm{fMRI}$ neurofeedback does not reinforce brain activity at the voxel level but at the level of a low-dimensional manifold instead. Indeed, multiple lines of evidence indicate that neural activity does not occur completely at random and is rather constrained on a low-dimensional manifold (Ringach, 2009). To test this hypothesis in the context of brain-computer interfaces $(\mathrm{BCl})$, Sadtler and colleagues determined a low-dimensional space from high-dimensional recordings of neuronal activity in macaque monkeys (Sadtler et al., 2014). They showed that the dimensions of that intrinsic manifold considerably constrained learning in a $\mathrm{BCl}$ task such that it was more difficult for the monkey to learn to generate patterns of brain activity that would fall outside of the manifold. These findings are important as they indicate that not all patterns of brain activity are equally likely to be trained using $\mathrm{BCl}$ or neurofeedback. This finding is corroborated, to some extent, by results in fMRI neurofeedback. More precisely, Shibata and colleagues showed that, during the induction period of decoded neurofeedback experiments, $80 \%$ of the variance of the blood oxygen level-dependent (BOLD) signal can be explained by a relatively small number of principal components (Shibata et al., 2019). Taken together, these results suggest that the space of possible activation patterns to explore during neurofeedback may be smaller than expected which could render tractable the complex learning problem posed by neurofeedback experiments (Watanabe et al., 2017).

Another outstanding question pertains to the precise mechanisms responsible for the regulation of brain activity. A meta-analysis of previous $\mathrm{fMRI}$ neurofeedback studies indicated that, across multiple neurofeedback targets, regulation primarily engaged the anterior insular cortex, the basal ganglia (primarily the striatum), the temporo-parietal area, the anterior cingulate cortex, the dorsolateral prefrontal cortex and the ventrolateral prefrontal cortex (Emmert et al., 2016). Similarly, a meta-analysis conducted exclusively on decoded fMRI neurofeedback studies also highlighted the involvement of the insular cortex, dorsal striatum, posterior parietal cortex, supplementary motor area and cerebellum (Shibata et al., 2019). One 
possibility is that these structures mediate reinforcement learning during the task. Here the feedback may act as a reward capable of reinforcing the occurrence of specific brain activity. In line with what we saw above, reinforcement learning may operate at the level of a low-dimensional manifold of neural activity (Sadtler et al., 2014; Shibata et al., 2019). Yet another possibility is that reinforcement learning might occur at the voxel level. Oblak and colleagues showed that, in simulated voxels, reinforcement could facilitate the expression of the targeted pattern of brain activity when spontaneous correlated activity was also present (Oblak, Sulzer and Lewis-Peacock, 2019). As such, these simulations indicate a potential mechanism capable of reinforcing specific patterns of brain activity using decoded fMRI neurofeedback (For a discussion of other theories of neurofeedback learning, see Sitaram et al., 2017).

Yet another outstanding question pertains to the mechanisms mediating therapeutic effects. This is of course of great importance to interventions specifically designed for mental disorders. Most interventions carried out attempted to "regularize" or "normalize" specific brain targets that have been identified as problematic in a clinical population. For instance, the amygdala reactivity in major depressive disorder (Young et al., 2014; Young, Misaki, et al., 2017; Young, Siegle, et al., 2017) or the functional connectivity between the superior temporal sulcus and the somatosensory cortex in autism spectrum disorder (Ramot et al., 2017). Of course, precise biomarkers of psychopathologies are still hotly debated. However, if neurofeedback training leads to clinical improvements, this could further indicate the link between the specific brain target and the clinical outcome at hand.

Decoded fMRI neurofeedback also presents interesting clinical applications as it makes it possible to target distributed brain representations rather than regional brain activity. Previous experiments indicated that it might be possible to target brain representations with specific significance for pathology, like representations of feared stimuli (Taschereau-Dumouchel et al., 2018; Chiba et al., 2019). Using this approach, it might be possible to achieve therapeutic 
effects by pairing, for instance, such representations with a reward or by training participants to repeatedly activate such representations in their brain. Concrete clinical applications will be discussed in the section: Promising approaches in the treatment of mental disorders.

\section{Common methodological considerations in the neurofeedback litterature}

Multiple factors are expected to modulate brain activity and behavior in neurofeedback experiments. If such confounds are not delineated properly, one is at risk of falsely attributing observed effects to neurofeedback interventions. Such considerations led researchers to mobilise and to develop guidelines in an attempt to bring more experimental rigour to the field (Ros et al., 2020). Below, we provide an overview of commonly discussed methodological considerations and some helpful guidelines to improve the interpretability of the results. Importantly, if such guidelines are observed, it is often possible to conduct experiments with the utmost scientific rigour.

\section{a. Control conditions and the possibility for double-blind interventions}

Control conditions are essential in order to isolate the intended effects of neurofeedback experiments. The control condition to be used is often defined by the goal of each individual experiment (Sorger et al., 2019). In a literature review, Thibault and colleagues reported that about $38 \%$ of fMRI neurofeedback experiments did not include a control group (Thibault et al., 2018). Such designs are appropriate when one primarily aims at studying the modulation of brain activity between regulation and rest blocks. However, when it comes to studying behavioral outcomes, control groups or control conditions are necessary in order to rule out the effect of confounds such as the placebo effect, the passage of time, non-specific effects of training and interaction with the research personnel (Sorger et al., 2019). A good strategy is to provide a control group with placebo neurofeedback. For instance, one can provide feedback 
using the activity of another brain region (Young et al., 2014; Young, Siegle, et al., 2017) or simply by inverting the feedback provided to the experimental group (Shibata et al., 2016). In these situations, the task demands and reward contingencies should be very similar between groups, which should provide adequate control of the placebo effect.

However, a control group is not always the best option. In fact, within-subject controls have the potential to be even more powerful as they also control for any other factor that could vary between groups and affect the results. They also require considerably less resources than control groups as they only require one experimental group to go through the training. Notably, such designs are appropriate when the effect of the intervention can be observed on specific experimental conditions but not on others (Shibata et al., 2011; Koizumi et al., 2016; Taschereau-Dumouchel et al., 2018; Taschereau-Dumouchel, Liu and Lau, 2018). Within-subject designs can also be devised such that participants will take part both in up-and down-regulation sessions (crossover design) (Cortese et al., 2016). In this context, participants act as their own control. When appropriate, within-subject designs can bring the strongest scientific demonstration while minimizing the resources required.

Further, in order to fully control for the placebo effect, it is important to make sure that both patients and experimenters are blind to the experimental conditions. Such experimental designs, termed double-blind experiments, represent the highest scientific standards but few psychological interventions can actually be conducted in such settings, as experimenters can often make educated guesses regarding the nature of the intervention. This is not the case with neurofeedback as blinding the experimenters is generally relatively straightforward. Once real-time processing pipelines are created, group membership can be randomly selected without the experimenters' knowledge. This is a simple step with important implications as it can shield researchers from unwillingly influencing participants' behavior. Surprisingly, this important feature of neurofeedback has been underappreciated in the past. As Thibault and colleagues 
reported, out of the many studies using placebo-controlled neurofeedback, only a handful were also reported to be conducted in double-blind settings (Paret et al., 2014; Young et al., 2014; Yuan et al., 2014; Guan et al., 2015; Hamilton et al., 2016; Paret, Ruf, et al., 2016; Yao et al., 2016; Zotev et al., 2016; Young, Misaki, et al., 2017; Young, Siegle, et al., 2017; Taschereau-Dumouchel et al., 2018).

\section{B. Explicit vs implicit neurofeedback}

Many previous neurofeedback experiments provided participants with an explicit training strategy such as instructions to engage in mental imagery or to retrieve positive affective memories (Sitaram et al., 2011; Scharnowski et al., 2012; Young et al., 2014; Zilverstand et al., 2015). It is commonly assumed that such strategies should help to create the desired effect. This approach is appropriate when the control and experimental groups are provided with the same strategies. However, if they are not, this is likely to create an interpretation problem as the effect of the strategy will be interwoven with the effect of neurofeedback.

Another approach has been to use implicit neurofeedback approaches, meaning that participants are not provided with any induction strategy in order to modulate their brain activity. This approach assumes that pairing the feedback with a monetary reward should be sufficient to reinforce the targeted brain activity. Importantly, this approach has been shown to outperform explicit neurofeedback in a study directly comparing implicit and explicit approaches (Sepulveda et al., 2016). Furthermore, multiple studies have reported substantial behavioral and neural effects using implicit approaches (Shibata et al., 2011; Cortese et al., 2016; Koizumi et al., 2016; Ramot et al., 2016, 2017). As such, implicit neurofeedback presents many advantages over explicit approaches. However, this should be taken with caution as only one study has directly compared implicit and explicit approaches. 


\section{Physiological artifacts}

fMRI neurofeedback experiments provide feedback based on the BOLD signal. Physiological artifacts can drastically influence this metric. For instance, the BOLD signal can be substantially modulated when participants are holding their breath (Kastrup et al., 1999; Abbott et al., 2005; Thomason et al., 2005). Furthermore, some have suggested that, during real time functional connectivity neurofeedback, regularity of breathing accounted for most of the correlation observed between brain regions (Weiss et al., 2020). As a result, participants could essentially learn, likely unconsciously, to modulate their breathing rate in order to perform better at the task. Such increased performance would not reflect a true modulation of brain activity, but rather a global change in blood oxygenation. In order to correct for such artifacts, some have suggested regressing out physiological signals and, in the case of functional connectivity neurofeedback, regressing out the global signal (Weiss et al., 2020). It is important to note however that not all neurofeedback approaches are equally likely to be affected. For instance, results of within-subject control designs are unlikely to be explained by such artifacts as experimental conditions are expected to be affected in similar ways by such physiological artifacts. Furthermore, decoded neurofeedback (see section Decoded Neurofeedback) relies both on positive and negative weights attributed to voxels within a given brain region. As a result, a global modulation of BOLD activity is not expected to affect the feedback in a straightforward manner (Shibata et al., 2019). This is an empirical question that should be addressed in future research.

\section{Promising approaches in the treatment of mental disorders}

Over the years, multiple psychopathologies have been targeted by fMRI neurofeedback interventions and great literature reviews have been written (Stoeckel et al., 2014; Tursic et al., 2020; Pindi et al., 2021). Here, we aim at presenting an overview of this literature by 
sub-selecting only the most scientifically rigorous studies. Based on two recent systematic reviews of the field (Tursic et al., 2020; Pindi et al., 2021), we sub-selected studies targeting a mental health disorder where: (1) patients were blinded to experimental goals and (2) a control group or control condition was included. Our approach is not meant to diminish the usefulness of proof-of-principle studies that may not fulfil these criteria (Paret, Kluetsch, et al., 2016; Orlov et al., 2018; Chiba et al., 2019; Zaehringer et al., 2019; Takamura et al., 2020; Mennen et al., 2021). Such studies are crucial in order to show target engagement before more extensive funding can be secured for larger clinical studies. However, when it comes to clinical efficacy, studies need to be on par with clinical research guidelines and present multiple experimental controls. As such, our approach aims at providing a bird's-eye view of the field based on minimally confounded studies (Thibault, Lifshitz and Raz, 2017). Further, we also included some studies conducted in subclinical populations that could potentially inform future clinical targets for neurofeedback.

Our selection method yielded 25 studies, all of which have been published since 2013 . Only a few studies have been conducted within each individual disorder and few have been pre-registered. As such, we propose to provide a qualitative assessment of this young field of research, noting the strengths and weaknesses of the studies conducted so far. Following the terminology used by the American Psychological Association, we found that treatment strategies using fMRI neurofeedback do not yet meet criteria for "well-established" treatments, but some approaches could be considered "probably efficacious" treatments (Chambless and Hollon, 1998; APA Presidential Task Force on Evidence-Based Practice, 2006). So far, fMRI neurofeedback interventions for major depressive disorder present the most empirical support. 


\section{a. Major depressive disorder}

Previous work indicated that depressed patients present a blunted activity of the amygdala when processing positive stimuli (Victor et al., 2010). Such findings inspired a treatment strategy aiming at increasing the activity of the amygdala during the processing of happy memories. Using this approach, multiple experiments have reported that the emotional state of patients in the active group can be improved in comparison to a control group (Young et al., 2014; Yuan et al., 2014; Zotev et al., 2016; Young, Siegle, et al., 2017). Importantly, this demonstration has been achieved in double-blind placebo-controlled experiments (Young et al., 2014; Yuan et al., 2014; Young, Siegle, et al., 2017). This constitutes a strong scientific demonstration of the usefulness of amygdala neurofeedback in order to improve the emotional state of depressed patients. Relatedly, other researchers attempted to modulate the affective bias of depressed patients by targeting the activity within the salience network. For instance, Hamilton and colleagues (2016) trained patients to regulate the activity within the insula and dorsal anterior cingulate cortex in hope of regularizing their perceptual bias. They showed, again in a double-blind placebo-controlled study, that their intervention decreased negative affects reported by patients when confronted with negative images. Taken together, these results constitute a strong scientific demonstration that $\mathrm{fMRI}$ neurofeedback may be useful in order to improve the emotional state of patients and to regularize their perceptual biases. It is however important to note that other approaches were not as successful (Mehler et al., 2018; Zotev et al., 2020).

\section{b. Anxiety disorders}

Other fMRI neurofeedback studies aimed at regularizing symptoms of anxiety disorders. In a study conducted with spider phobic patients, Zilverstand and colleagues reported that dual neurofeedback of the dorsolateral prefrontal cortex and insula decreased anxiety during 
exposure to the feared animal following the intervention (Zilverstand et al., 2015). While these results are very informative, it is important to note that different induction strategies were provided to the active and control groups (cognitive reappraisal vs rest). As such, the reported results may be partly attributed to the cognitive reappraisal strategy used in the active group.

Other approaches aimed at targeting brain structures involved in the regulation of physiological defensive responses to threat. For instance, in a subclinical population presenting high contamination-related anxiety, Scheinost and colleagues reported that fMRI neurofeedback of the orbitofrontal cortex was associated with an increased perception of control over contamination anxiety (Scheinost et al., 2013). Relatedly, Zhao and colleagues showed that neurofeedback of the functional connectivity between the amygdala and the ventromedial prefrontal cortex decreased self-reported anxiety in a subclinical population presenting high trait anxiety (Zhao et al., 2019). Taken together, these findings strongly suggest that fMRI neurofeedback can help regulate anxiety symptoms in subclinical populations.

Yet another approach might be to target upstream the association between sensory representations and physiological defensive responses. For instance, we showed, in a double-blind fMRI neurofeedback experiment, that it is possible to decrease physiological defensive responses to feared animals (i.e., amygdala and skin conductance reactivity). This was achieved by training participants to pair a reward with the activation likelihood of the brain decoder of a feared animal (Taschereau-Dumouchel et al., 2018). These results are important as they indicate that it might be possible to change unconsciously how sensory representations generate physiological defensive responses. This intervention was carried out in a subclinical population and further investigations will be needed in order to establish the potential for clinical applications. 


\section{c. Substance abuse}

fMRI neurofeedback has also been used in order to decrease cravings in substance abuse. Two studies were conducted with nicotine-dependent smokers. The goal of the first one was to reduce cravings by training participants to regulate the activity within craving-related regions located in the anterior cingulate cortex and medial prefrontal cortex. The results showed a between-group effect with participants in the active group presenting a greater decrease in the urge to smoke following the intervention (Hartwell et al., 2016). In the second study, Kim and colleagues investigated the added value of including a functional connectivity component to the feedback. To do so, they provided two groups of heavy smokers with different feedback. The first group received feedback from the anterior cingulate cortex, medial prefrontal cortex and orbitofrontal cortex. The second one received feedback from the same regions but also from the functional connectivity between these regions and the posterior cingulate cortex and precuneus. They showed that including information about functional connectivity may have an effect on reducing cravings (Kim et al., 2015). However, the between-group effect was not reported. These results indicate that fMRI neurofeedback may be helpful in order to decrease cravings in nicotine-dependent smokers, but further investigations conducted in double-blind placebo-controlled interventions are currently needed.

\section{d. Attention deficit / hyperactivity disorder}

Multiple studies suggested that EEG neurofeedback might be a potential treatment for attention deficit / hyperactivity disorder (Arns et al., 2009; Sonuga-Barke et al., 2013; Holtmann et al., 2014). However, surprisingly little evidence also supports this possibility when it comes to fMRI neurofeedback. For instance, Alegria and colleagues conducted an fMRI neurofeedback study with adolescents presenting attention deficit / hyperactivity disorder. They showed that patients could learn to regulate brain activity within the right inferior frontal gyrus. However, they 
reported no between-group effect on the main clinical outcomes (Alegria et al., 2017). Similar results were also obtained by Zilverstand and colleagues (Zilverstand et al., 2017). They showed that patients can learn to modulate the activity within the dorsal anterior cingulate cortex. However, while they observed some improvements in cognitive functioning (i.e., sustained visual attention and visual working memory), they did not observe between-group effects on the main clinical outcomes.

Such discrepancies between EEG and fMRI approaches may be partly explained by methodological differences as the two imaging methods are vastly different. This begs the question: could other fMRI approaches also present therapeutic effects? Interestingly, a decoded $\mathrm{fMRI}$ neurofeedback experiment indicated that sustained visual attention might be efficiently trained in healthy participants. De Bettencourt and colleagues designed an intervention where mixture images composed of face and scene stimuli were presented in the fMRI scanner and updated in real time as a function of the decoded brain activity (deBettencourt et al., 2015). If the decoder output indicated a greater representation of the task-relevant category (either face or scene) the mixture image was updated in order to represent this category more clearly on the computer screen. Importantly, this intervention was shown to increase sensitivity in a sustained attention task following neurofeedback training. These results suggest the possibility of training sustained attention in healthy individuals and might present interesting clinical applications for attention deficit / hyperactivity disorder but also for major depressive disorder. For instance, a recent proof-of-concept study showed the potential of this approach to reduce the negative attentional bias in depressed patients (This study was not included in Table 1 and in the section on Major depressive disorders as we could not establish if the study was single-blind) (Mennen et al., 2021). 


\section{e. Autism spectrum disorder}

Autism spectrum disorder has been associated with various dysregulations in the functional connectivity of the brain. Notably, under-connectivity has been reported between various brain regions (Müller et al., 2011). As such, one possibility for symptom management might be to reinforce some connections using functional connectivity neurofeedback. Ramot and colleagues designed an experiment to achieve this goal (Ramot et al., 2017). First, they leveraged resting-state connectivity data from participants presenting autism spectrum disorder and from typically developing individuals. Using this data, they established that autism spectrum participants presented with decreased connectivity between the superior temporal sulcus and the somatosensory cortex. Using a new feedback method called the two-point approach (see Fig. 3b), they trained autism spectrum participants to increase the connectivity between these two regions while decreasing the connectivity between these regions and a control region. Importantly, the intervention was carried in such a way that participants were not even aware of taking part in a neurofeedback experiment. Ramot and colleagues showed that autism spectrum participants learned, completely unconsciously, to increase the connectivity between the two target regions. Furthermore, the change in resting state connectivity following the intervention was associated with positive behavioral changes in the autism spectrum participants. While it is still unclear if this approach can also lead to between-group effects, these results are nevertheless very informative and warrant further investigations of the approach.

\section{f. Post-traumatic stress disorder}

Another mental health disorder that represents a considerable therapeutic challenge is post-traumatic stress disorder. Previous neurofeedback approaches have been used with mixed results in this population. For instance, Zotev and colleagues conducted an fMRI / EEG neurofeedback experiment with patients presenting post-traumatic stress disorder (Zotev et al., 
2018). They did not observe any between-group effect on clinically meaningful outcomes (such as CAPS scores), but they did observe a trend towards significance. Furthermore, the intervention helped to regulate the functional connectivity of the amygdala with diverse regions of the prefrontal cortex including the dorsolateral prefrontal cortex. As such, further investigations using a pre-registered intervention appear to be warranted.

Yet another approach conducted in a healthy population might present interesting clinical applications in the future. Keynan and colleagues used an EEG-fingerprint approach (see Fig. 3a) to train stress resilience in men enrolled in military training (Keynan et al., 2019). Their goal was to provide neurofeedback training in order to prevent stress-induced psychopathologies. They showed that training participants to regulate the EEG-fingerprint of the amygdala could improve emotion regulation as evidenced by decreased alexithymia and improved emotional stroop task performances. This could represent an interesting avenue in order to prevent the effect of stressful situations on mental health.

\section{g. Schizophrenia}

Lastly, some researchers also aimed at reducing auditory hallucinations in schizophrenia patients using fMRI neurofeedback. For instance, Zweerings and colleagues conducted an intervention where schizophrenia patients were trained to regulate the activity within the Inferior frontal gyrus and the superior temporal gyrus (Zweerings et al., 2019). Following this intervention, the authors observed a negative association between the connectivity between these two regions and the global severity index. Further, two recent studies reported a decrease in auditory hallucinations following interventions targeting the superior temporal gyrus and the ratio of activation between the central executive network and the default mode network (Bauer et al., 2020; Okano et al., 2020). While these studies were conducted in rigorous designs it is important to note that these effects were observed within-groups (or within-conditions) and that 
no between-group (or between-conditions) effects were reported. Nevertheless, these findings warrants further investigation into the possibility of reducing auditory hallucinations with fMRI neurofeedback.

\section{Future directions and conclusion}

The field of fMRI neurofeedback is still young. Recently, multiple initiatives have been taken to bring more scientific rigour to the field (Ros et al., 2020). Such concerns are being taken seriously and, as a result, the full scientific potential of neurofeedback interventions has started to show. Recent studies conducted with stringent scientific rigour have indeed shown the potential to achieve very specific therapeutic effects in clinical populations (Young, Siegle, et al., 2017). Moving forward, this should pave the way for more pre-registered clinical trials conducted in double-blind placebo-controlled settings. At this stage, such diligent empirical demonstrations are necessary in order to further establish the usefulness of fMRI neurofeedback as a general treatment strategy in mental health.

Moving forward, one can imagine multiple ways to improve current neurofeedback approaches. For instance, only a few studies previously used advanced neurofeedback approaches such as decoded neurofeedback and EEG-fingerprinting with clinical populations. Using such methods, it should be possible to improve the sensitivity and specificity of neurofeedback interventions and to simultaneously improve therapeutic effects. Furthermore, one can imagine multiple new therapeutic approaches based on current research findings in the field. For instance, Cortese and colleagues showed that neurofeedback might be used in order to improve meta-cognition and the capacity to perceive one's own brain activity (Cortese et al., 2016; Cortese, Lau and Kawato, 2020). Notably, such approaches might be leveraged in order to train meta-cognitive deficits in clinical populations. Other future applications might include targeting the production of specific neurotransmitters (Maclnnes et al., 2016). For instance, 
Maclnnes and colleagues showed that participants can be trained to increase the activity within the ventral tegmental area, a brain region associated with striatal dopamine release (Schott et al., 2008). While further investigations are still needed in order to precisely document changes in dopamine release, such an approach presents an interesting future avenue for intervention. Clinical populations presenting a dysregulation of the dopamine system could potentially regulate neurotransmitter levels without medication. The targeted specificity of such a neurofeedback approach could avoid the undesirable side effects of common neurotransmitter-regulating medications. Lastly, another means of intervention might be to combine neurofeedback with in-scanner virtual reality (Lorenzetti et al., 2018). This approach could notably be used to improve the decoding of specific brain states and to devise new reinforcing environments capable of improving learning beyond current approaches.

We have come a long way since the first demonstrations to suggest the direct reinforcement of neural responses in the brain. However, devising effective therapeutic strategies using neurofeedback techniques is a complex endeavor requiring multiple iterations. We now have multiple lines of evidence suggesting that neurofeedback interventions can have very precise therapeutic effects in mental health. Considering that new machine learning approaches can potentially potentiate the effects in the field, we are optimistic that multiple new approaches will be successfully tested in the future. Importantly, we have entered an era of research where such interventions will be evaluated with the utmost scientific rigor. As such, we are confident that future studies will be able to further delineate the usefulness of fMRI neurofeedback as a therapeutic approach in mental health. 


\section{Acknowledgments}

Dr. Lau would like to thank the Templeton World Charity Foundation (RA537-01) for their financial support. Dr. Taschereau-Dumouchel would like to thank the US National Institute of Mental Health (R61MH113772) and the Canadian Institute of Health Research (CIHR) for their financial support. 


\section{Terms and Definitions}

Closed-loop brain imaging: General family of approaches leveraging real-time brain imaging for the purpose of brain regulation.

Neurofeedback: A kind of biofeedback where participants are provided with information regarding their own brain activity for the purpose of regulation.

Decoded neurofeedback: A neurofeedback approach that uses machine learning to determine the intervention target. It also involves monetary rewards and implicit strategies.

Brain-computer interface: A real-time brain imaging approach aiming at controlling an external device through the modulation of brain activity.

Co-adaptive systems: Closed-loop systems where the user and the machine aim at regulating brain activity by adapting their behavior or neural activity. 


\section{Related Resources}

The DecNef Collection: A database regrouping the data of multiple previous decoded neurofeedback experiments (https://bicr-resource.atr.jp/drmd/) (Cortese et al., 2021).

Softwares available to conduct neurofeedback experiments:

ATR toolbox: This free software can be used for the purpose of conducting experiments in decoded neurofeedback and functional connectivity neurofeedback (https://bicr.atr.jp/decnefpro/).

BrainIAK: This free software can be used to conduct multiple real-time brain imaging experiments. Notably, it can be used to conduct cloud-based interventions (https://brainiak.org/examples/rtcloud notebook.html) (Kumar et al., 2020).

MURFI: This free software can be used to conduct multivariate and univariate neurofeedback interventions (https://github.com/gablab/murfi2) (Hinds et al., 2011).

OpenNFT: This free software can be used to conduct diverse neurofeedback experiments such as univariate, multivariate and connectivity neurofeedback (http://opennft.org) (Koush, Ashburner, et al., 2017).

Pyneal: This free software can be used to conduct univariate neurofeedback experiments It includes a tool to transform mask from MNI space to the native space of a participant (https://github.com/jeffmacinnes/pyneal) (Maclnnes et al., 2020).

Turbo BrainVoyager: This paid software can be used to conduct multiple neurofeedback experiments (https://www.brainvoyager.com/downloads/install turbobrainvoyager.html) (Goebel, Esposito and Formisano, 2006). 


\section{Literature Cited}

Abbott, D. F. et al. (2005) 'Brief breath holding may confound functional magnetic resonance imaging studies', Human brain mapping, 24(4), pp. 284-290.

Alegria, A. A. et al. (2017) 'Real-time fMRI neurofeedback in adolescents with attention deficit hyperactivity disorder', Human brain mapping, 38(6), pp. 3190-3209.

Amano, K. et al. (2016) 'Learning to Associate Orientation with Color in Early Visual Areas by Associative Decoded fMRI Neurofeedback', Current Biology, pp. 1861-1866. doi: 10.1016/j.cub.2016.05.014.

APA Presidential Task Force on Evidence-Based Practice (2006) 'Evidence-based practice in psychology', The American psychologist, 61(4), pp. 271-285.

Arns, M. et al. (2009) 'Efficacy of Neurofeedback Treatment in ADHD: The Effects on Inattention, Impulsivity and Hyperactivity: A Meta-Analysis', Clinical EEG and Neuroscience, pp. 180-189. doi: 10.1177/155005940904000311.

Avena-Koenigsberger, A., Misic, B. and Sporns, O. (2018) 'Communication dynamics in complex brain networks', Nature Reviews Neuroscience, pp. 17-33. doi: 10.1038/nrn.2017.149.

Bagarinao, E. et al. (2003) 'Estimation of general linear model coefficients for real-time application', Neurolmage, 19(2 Pt 1), pp. 422-429.

Bashivan, P., Kar, K. and DiCarlo, J. J. (2019) 'Neural population control via deep image synthesis', Science, 364(6439). doi: 10.1126/science.aav9436.

Bassett, D. S. and Sporns, O. (2017) 'Network neuroscience', Nature neuroscience, 20, pp. 353-364.

Bauer, C. C. C. et al. (2020) 'Real-time fMRI neurofeedback reduces auditory hallucinations and modulates resting state connectivity of involved brain regions: Part 2: Default mode network -preliminary evidence', Psychiatry research, 284, p. 112770.

Beatty, J. et al. (1974) 'Operant control of occipital theta rhythm affects performance in a radar monitoring task', Science, 183(4127), pp. 871-873.

Bu, J. et al. (2019) 'Effect of deactivation of activity patterns related to smoking cue reactivity on nicotine addiction', Brain: a journal of neurology, 142(6), pp. 1827-1841.

Chambless, D. L. and Hollon, S. D. (1998) 'Defining empirically supported therapies', Journal of consulting and clinical psychology, 66(1), pp. 7-18.

Chen, P.-H. et al. (2015) 'A Reduced-Dimension fMRI Shared Response Model', in NIPS. researchgate.net, pp. 460-468.

Chiba, T. et al. (2019) 'Current Status of Neurofeedback for Post-traumatic Stress Disorder: A Systematic Review and the Possibility of Decoded Neurofeedback', Frontiers in human neuroscience, 13, p. 233.

Cohen, J. D. et al. (2017) 'Computational approaches to fMRI analysis', Nature neuroscience, 
20(3), pp. 304-313.

Cohen, M. S. (2001) 'Real-time functional magnetic resonance imaging', Methods , 25(2), pp. 201-220.

Cortese, A. et al. (2016) 'Multivoxel neurofeedback selectively modulates confidence without changing perceptual performance', Nature communications, 7, p. 13669.

Cortese, A. et al. (2021) 'The DecNef collection, fMRI data from closed-loop decoded neurofeedback experiments', Scientific data, 8(1), p. 65.

Cortese, A., Lau, H. and Kawato, M. (2020) 'Unconscious reinforcement learning of hidden brain states supported by confidence', Nature communications, 11, p. 4429.

Cox, R. W. and Jesmanowicz, A. (1999) 'Real-time 3D image registration for functional MRI', Magnetic Resonance in Medicine, 42(6), pp. 1014-1018.

Cox, R. W., Jesmanowicz, A. and Hyde, J. S. (1995) 'Real-time functional magnetic resonance imaging', Magnetic resonance in medicine: official journal of the Society of Magnetic Resonance in Medicine / Society of Magnetic Resonance in Medicine, 33(2), pp. 230-236.

deBettencourt, M. T. et al. (2015) 'Closed-loop training of attention with real-time brain imaging', Nature neuroscience, 18(3), pp. 470-475.

Eklund, A. et al. (2014) 'BROCCOLI: Software for fast fMRI analysis on many-core CPUs and GPUs', Frontiers in neuroinformatics, 8, p. 24.

Emmert, K. et al. (2016) 'Meta-analysis of real-time fMRI neurofeedback studies using individual participant data: How is brain regulation mediated?', Neurolmage, 124(Pt A), pp. 806-812.

Fetz, E. E. (1969) 'Operant Conditioning of Cortical Unit Activity', Science, pp. 955-958. doi: 10.1126/science.163.3870.955.

Fetz, E. E. and Finocchio, D. V. (1971) 'Operant conditioning of specific patterns of neural and muscular activity', Science, 174(4007), pp. 431-435.

Fonov, V. S. et al. (2009) 'Unbiased nonlinear average age-appropriate brain templates from birth to adulthood', Neurolmage, Supplement 1(47), p. S102.

Gembris, D. et al. (2000) 'Functional magnetic resonance imaging in real time (FIRE): Sliding-window correlation analysis and reference-vector optimization', Magnetic Resonance in Medicine: An Official Journal of the International Society for Magnetic Resonance in Medicine, 43(2), pp. 259-268.

Goddard, N. et al. (1997) 'Online Analysis of Functional MRI Datasets on Parallel Platforms', The Journal of supercomputing, 11(3), pp. 295-318.

Goebel, R., Esposito, F. and Formisano, E. (2006) 'Analysis of FIAC data with BrainVoyager QX: from single-subject to cortically aligned group GLM analysis and self-organizing group ICA', Human brain mapping, 27(5), pp. 392-401.

Goodfellow, I. et al. (2016) Deep learning. MIT press Cambridge. 
Greenberg, G. (2013) 'The psychiatric drug crisis', New Yorker , 3. Available at: https://www.betterdaysandnights.com/The\%20Psychiatric\%20Drug\%20Crisis.pdf.

Griebel, G. and Holmes, A. (2013) '50 years of hurdles and hope in anxiolytic drug discovery', Nature reviews. Drug discovery, 12(9), pp. 667-687.

Guan, M. et al. (2015) 'Self-regulation of brain activity in patients with postherpetic neuralgia: a double-blind randomized study using real-time FMRI neurofeedback', PloS one, 10(4), p. e0123675.

Hamilton, J. P. et al. (2016) 'Effects of salience-network-node neurofeedback training on affective biases in major depressive disorder', Psychiatry research. Neuroimaging, 249, pp. 91-96.

Hartwell, K. J. et al. (2016) 'Individualized real-time fMRI neurofeedback to attenuate craving in nicotine-dependent smokers', Journal of psychiatry \& neuroscience: JPN, 41(1), pp. 48-55.

Haxby, J. V. et al. (2001) 'Distributed and overlapping representations of faces and objects in ventral temporal cortex', Science, 293(5539), pp. 2425-2430.

Haxby, J. V. et al. (2011) 'A common, high-dimensional model of the representational space in human ventral temporal cortex', Neuron, 72(2), pp. 404-416.

Haxby, J. V., Connolly, A. C. and Guntupalli, J. S. (2014) 'Decoding neural representational spaces using multivariate pattern analysis', Annual review of neuroscience, 37, pp. 435-456.

Hinds, O. et al. (2011) 'Computing moment-to-moment BOLD activation for real-time neurofeedback', Neurolmage, 54(1), pp. 361-368.

Holtmann, M. et al. (2014) 'Neurofeedback for ADHD: a review of current evidence', Child and adolescent psychiatric clinics of North America, 23(4), pp. 789-806.

Hyman, S. E. (2012) 'Revolution stalled', Science translational medicine, 4(155), p. 155cm11.

Kamiya, J. (1962) 'Conditioned discrimination of the EEG alpha rhythm in humans', Western Psychological Association, San Francisco, CA.

Kamiya, J. (1966) 'Trained control of EEG alpha frequency in humans', Invited presentation, California: Stanford University, Palo Alto.

Kamiya, J. (1968) 'Conscious Control of Brain Waves', Psychology today, 1, pp. 56-60.

Kamiya, J. (2011) 'The First Communications About Operant Conditioning of the EEG', Journal of neurotherapy, 15(1), pp. 65-73.

Kastrup, A. et al. (1999) 'Assessment of cerebral oxidative metabolism with breath holding and fMRI', Magnetic resonance in medicine: official journal of the Society of Magnetic Resonance in Medicine / Society of Magnetic Resonance in Medicine, 42(3), pp. 608-611.

Keynan, J. N. et al. (2016) 'Limbic Activity Modulation Guided by Functional Magnetic Resonance Imaging-Inspired Electroencephalography Improves Implicit Emotion Regulation', Biological psychiatry, 80(6), pp. 490-496. 
Keynan, J. N. et al. (2019) 'Electrical fingerprint of the amygdala guides neurofeedback training for stress resilience', Nature human behaviour, 3(1), pp. 63-73.

Kim, D.-Y. et al. (2015) 'The inclusion of functional connectivity information into fMRI-based neurofeedback improves its efficacy in the reduction of cigarette cravings', Journal of cognitive neuroscience, 27(8), pp. 1552-1572.

Koizumi, A. et al. (2016) 'Fear reduction without fear through reinforcement of neural activity that bypasses conscious exposure', Nature human behaviour, 1. doi:

10.1038/s41562-016-0006.

Koush, Y. et al. (2013) 'Connectivity-based neurofeedback: dynamic causal modeling for real-time fMRI', Neurolmage, 81, pp. 422-430.

Koush, Y., Meskaldji, D.-E., et al. (2017) 'Learning Control Over Emotion Networks Through Connectivity-Based Neurofeedback', Cerebral cortex , 27(2), pp. 1193-1202.

Koush, Y., Ashburner, J., et al. (2017) 'OpenNFT: An open-source Python/Matlab framework for real-time fMRI neurofeedback training based on activity, connectivity and multivariate pattern analysis', Neurolmage, 156, pp. 489-503.

Koush, Y. et al. (2019) 'Data-driven tensor independent component analysis for model-based connectivity neurofeedback', Neurolmage, 184, pp. 214-226.

Kumar, M. et al. (2020) 'BrainIAK tutorials: User-friendly learning materials for advanced fMRI analysis', PLoS computational biology, 16(1), p. e1007549.

Kwong, K. K. et al. (1992) 'Dynamic magnetic resonance imaging of human brain activity during primary sensory stimulation', Proceedings of the National Academy of Sciences of the United States of America, 89(12), pp. 5675-5679.

LaConte, S. M., Peltier, S. J. and Hu, X. P. (2007) ‘Real-time fMRI using brain-state classification', Human brain mapping, 28(10), pp. 1033-1044.

LeCun, Y., Bengio, Y. and Hinton, G. (2015) 'Deep learning', Nature, 521(7553), pp. 436-444.

Lorenzetti, V. et al. (2018) 'Emotion Regulation Using Virtual Environments and Real-Time fMRI Neurofeedback', Frontiers in neurology, 9, p. 390.

Maclnnes, J. J. et al. (2016) 'Cognitive Neurostimulation: Learning to Volitionally Sustain Ventral Tegmental Area Activation', Neuron, 89(6), pp. 1331-1342.

MacInnes, J. J. et al. (2020) 'Pyneal: Open Source Real-Time fMRI Software', Frontiers in neuroscience, 14 , p. 900.

Mathiak, K. and Posse, S. (2001) 'Evaluation of motion and realignment for functional magnetic resonance imaging in real time', Magnetic resonance in medicine: official journal of the Society of Magnetic Resonance in Medicine / Society of Magnetic Resonance in Medicine, 45(1), pp. $167-171$.

Megumi, F. et al. (2015) 'Functional MRI neurofeedback training on connectivity between two regions induces long-lasting changes in intrinsic functional network', Frontiers in human 
neuroscience, 9, p. 160.

Mehler, D. M. A. et al. (2018) 'Targeting the affective brain-a randomized controlled trial of real-time fMRI neurofeedback in patients with depression', Neuropsychopharmacology: official publication of the American College of Neuropsychopharmacology, 43(13), pp. 2578-2585.

Mennen, A. C. et al. (2021) 'Cloud-Based Functional Magnetic Resonance Imaging Neurofeedback to Reduce the Negative Attentional Bias in Depression: A Proof-of-Concept Study', Biological psychiatry. Cognitive neuroscience and neuroimaging, 6(4), pp. 490-497.

Miller, G. (2010) 'Is pharma running out of brainy ideas?', Science, 329(5991), pp. 502-504.

Misaki, M. et al. (2018) 'Real-time fMRI amygdala neurofeedback positive emotional training normalized resting-state functional connectivity in combat veterans with and without PTSD: a connectome-wide investigation', Neurolmage: Clinical, 20, pp. 543-555.

Moore, G. (2021) 'Cramming More Components onto Integrated Circuits (1965)', Ideas That Created the Future, pp. 261-266. doi: 10.7551/mitpress/12274.003.0027.

Müller, R.-A. et al. (2011) 'Underconnected, but how? A survey of functional connectivity MRI studies in autism spectrum disorders', Cerebral cortex , 21(10), pp. 2233-2243.

Oblak, E. F., Sulzer, J. S. and Lewis-Peacock, J. A. (2019) 'A simulation-based approach to improve decoded neurofeedback performance', Neurolmage, 195, pp. 300-310.

Ogawa, S. et al. (1992) 'Intrinsic signal changes accompanying sensory stimulation: functional brain mapping with magnetic resonance imaging', Proceedings of the National Academy of Sciences of the United States of America, 89(13), pp. 5951-5955.

Okano, K. et al. (2020) 'Real-time fMRI feedback impacts brain activation, results in auditory hallucinations reduction: Part 1: Superior temporal gyrus -Preliminary evidence', Psychiatry research, 286, p. 112862.

Orlov, N. D. et al. (2018) 'Real-time fMRI neurofeedback to down-regulate superior temporal gyrus activity in patients with schizophrenia and auditory hallucinations: a proof-of-concept study', Translational psychiatry, 8(1), pp. 1-10.

Paret, C. et al. (2014) 'Down-regulation of amygdala activation with real-time fMRI neurofeedback in a healthy female sample', Frontiers in behavioral neuroscience, 8, p. 299.

Paret, C., Kluetsch, R., et al. (2016) 'Alterations of amygdala-prefrontal connectivity with real-time fMRI neurofeedback in BPD patients', Social cognitive and affective neuroscience, 11(6), pp. 952-960.

Paret, C., Ruf, M., et al. (2016) 'fMRI neurofeedback of amygdala response to aversive stimuli enhances prefrontal-limbic brain connectivity', Neurolmage, 125, pp. 182-188.

Pindi, P. et al. (2021) 'Real-time fMRI neurofeedback as a new treatment for psychiatric disorders: a systematic review', psyArxiv. doi: 10.31234/osf.io/r89sn.

Ponce, C. R. et al. (2019) 'Evolving Images for Visual Neurons Using a Deep Generative Network Reveals Coding Principles and Neuronal Preferences', Cell, 177(4), pp. 999-1009.e10. 
Posse, S. et al. (2001) 'A new approach to measure single-event related brain activity using real-time fMRI: feasibility of sensory, motor, and higher cognitive tasks', Human brain mapping, 12(1), pp. 25-41.

Posse, S. et al. (2003) 'Real-time fMRI of temporolimbic regions detects amygdala activation during single-trial self-induced sadness', Neurolmage, 18(3), pp. 760-768.

Ramot, M. et al. (2016) 'Covert neurofeedback without awareness shapes cortical network spontaneous connectivity', Proceedings of the National Academy of Sciences, pp.

E2413-E2420. doi: 10.1073/pnas.1516857113.

Ramot, M. et al. (2017) 'Direct modulation of aberrant brain network connectivity through real-time NeuroFeedback', eLife. doi: 10.7554/elife.28974.

Ramot, M. and Gonzalez-Castillo, J. (2019) 'A framework for offline evaluation and optimization of real-time algorithms for use in neurofeedback, demonstrated on an instantaneous proxy for correlations', Neurolmage, 188, pp. 322-334.

Ringach, D. L. (2009) 'Spontaneous and driven cortical activity: implications for computation', Current opinion in neurobiology, 19(4), pp. 439-444.

Ros, T. et al. (2020) 'Consensus on the reporting and experimental design of clinical and cognitive-behavioural neurofeedback studies (CRED-nf checklist)', Brain: a journal of neurology, 143(6), pp. 1674-1685.

Rubia, K. et al. (2019) 'Functional connectivity changes associated with fMRI neurofeedback of right inferior frontal cortex in adolescents with ADHD', Neurolmage, 188, pp. 43-58.

Sadtler, P. T. et al. (2014) 'Neural constraints on learning', Nature, 512(7515), pp. 423-426.

Scharnowski, F. et al. (2012) 'Improving visual perception through neurofeedback', The Journal of neuroscience: the official journal of the Society for Neuroscience, 32(49), pp. 17830-17841.

Scheinost, D. et al. (2013) 'Orbitofrontal cortex neurofeedback produces lasting changes in contamination anxiety and resting-state connectivity', Translational psychiatry, 3, p. e250.

Schott, B. H. et al. (2008) 'Mesolimbic functional magnetic resonance imaging activations during reward anticipation correlate with reward-related ventral striatal dopamine release', The Journal of neuroscience: the official journal of the Society for Neuroscience, 28(52), pp. 14311-14319.

Sepulveda, P. et al. (2016) 'How feedback, motor imagery, and reward influence brain self-regulation using real-time fMRl', Human brain mapping, 37(9), pp. 3153-3171.

Shibata, K. et al. (2011) 'Perceptual learning incepted by decoded fMRI neurofeedback without stimulus presentation', Science, 334(6061), pp. 1413-1415.

Shibata, K. et al. (2016) 'Differential Activation Patterns in the Same Brain Region Led to Opposite Emotional States', PLoS biology, 14(9), p. e1002546.

Shibata, K. et al. (2019) 'Toward a comprehensive understanding of the neural mechanisms of decoded neurofeedback', Neurolmage, 188, pp. 539-556.

Sirotin, Y. B. and Das, A. (2009) 'Anticipatory haemodynamic signals in sensory cortex not 
predicted by local neuronal activity', Nature, 457(7228), pp. 475-479.

Sitaram, R. et al. (2011) 'Real-time support vector classification and feedback of multiple emotional brain states', Neurolmage, 56(2), pp. 753-765.

Sitaram, R. et al. (2017) 'Closed-loop brain training: the science of neurofeedback', Nature reviews. Neuroscience, 18(2), pp. 86-100.

Smyser, C. et al. (2001) 'Real-time multiple linear regression for fMRI supported by time-aware acquisition and processing', Magnetic Resonance in Medicine: An Official Journal of the International Society for Magnetic Resonance in Medicine, 45(2), pp. 289-298.

Sonuga-Barke, E. J. S. et al. (2013) 'Nonpharmacological interventions for ADHD: systematic review and meta-analyses of randomized controlled trials of dietary and psychological treatments', The American journal of psychiatry, 170(3), pp. 275-289.

Sorger, B. et al. (2019) 'Control freaks: Towards optimal selection of control conditions for fMRI neurofeedback studies', Neurolmage, 186, pp. 256-265.

Srinivasan, R. et al. (1996) 'Spatial sampling and filtering of EEG with spline laplacians to estimate cortical potentials', Brain topography, 8(4), pp. 355-366.

Sterman, M. B., Howe, R. C. and Macdonald, L. R. (1970) 'Facilitation of spindle-burst sleep by conditioning of electroencephalographic activity while awake', Science, 167(3921), pp. 1146-1148.

Stoeckel, L. E. et al. (2014) 'Optimizing real time fMRI neurofeedback for therapeutic discovery and development', Neurolmage. Clinical, 5, pp. 245-255.

Sulzer, J. et al. (2013) 'Real-time fMRI neurofeedback: progress and challenges', Neurolmage, 76, pp. 386-399.

Takamura, M. et al. (2020) 'Antidepressive effect of left dorsolateral prefrontal cortex neurofeedback in patients with major depressive disorder: A preliminary report', Journal of affective disorders, 271, pp. 224-227.

Taschereau-Dumouchel, V. et al. (2018) 'Towards an unconscious neural reinforcement intervention for common fears', Proceedings of the National Academy of Sciences of the United States of America, 115(13), pp. 3470-3475.

Taschereau-Dumouchel, V., Kawato, M. and Lau, H. (2020) 'Multivoxel pattern analysis reveals dissociations between subjective fear and its physiological correlates', Molecular psychiatry, 25, pp. 2342-2354.

Taschereau-Dumouchel, V., Liu, K.-Y. and Lau, H. (2018) 'Unconscious Psychological Treatments for Physiological Survival Circuits', Current opinion in behavioral sciences, 24, pp. 62-68.

Taschereau-Dumouchel, V. and Roy, M. (2020) 'Could Brain Decoding Machines Change Our Minds?', Trends in cognitive sciences. doi: 10.1016/j.tics.2020.09.006.

Thibault, R. T. et al. (2018) 'Neurofeedback with fMRI: A critical systematic review', Neurolmage, 
172, pp. $786-807$.

Thibault, R. T., Lifshitz, M. and Raz, A. (2017) 'Neurofeedback or neuroplacebo?', Brain: a journal of neurology, pp. 862-864.

Thomason, M. E. et al. (2005) 'Breath holding reveals differences in fMRI BOLD signal in children and adults', Neurolmage, 25(3), pp. 824-837.

Tursic, A. et al. (2020) 'A systematic review of fMRI neurofeedback reporting and effects in clinical populations', Neurolmage. Clinical, 28, p. 102496.

Varoquaux, G. (2018) 'Cross-validation failure: Small sample sizes lead to large error bars', Neurolmage, pp. 68-77. doi: 10.1016/j.neuroimage.2017.06.061.

Victor, T. A. et al. (2010) 'Relationship between amygdala responses to masked faces and mood state and treatment in major depressive disorder', Archives of general psychiatry, 67(11), pp. $1128-1138$.

Voyvodic, J. T. (1999) 'Real-time fMRI paradigm control, physiology, and behavior combined with near real-time statistical analysis', Neurolmage, 10(2), pp. 91-106.

Wager, T. D. et al. (2013) 'An fMRI-Based Neurologic Signature of Physical Pain', New England Journal of Medicine, pp. 1388-1397. doi: 10.1056/nejmoa1204471.

Wang, Y. et al. (2016) 'Real-time full correlation matrix analysis of fMRI data', in 2016 IEEE International Conference on Big Data (Big Data). ieeexplore.ieee.org, pp. 1242-1251.

Watanabe, T. et al. (2017) 'Advances in fMRI Real-Time Neurofeedback', Trends in cognitive sciences, 21(12), pp. 997-1010.

Weiskopf, N. et al. (2003) 'Physiological self-regulation of regional brain activity using real-time functional magnetic resonance imaging (fMRI): methodology and exemplary data', Neurolmage, 19(3), pp. 577-586.

Weiskopf, N., Mathiak, K., et al. (2004) 'Principles of a brain-computer interface (BCl) based on real-time functional magnetic resonance imaging (fMRI)', IEEE transactions on bio-medical engineering, 51(6), pp. 966-970.

Weiskopf, N., Scharnowski, F., et al. (2004) 'Self-regulation of local brain activity using real-time functional magnetic resonance imaging (fMRI)', Journal of physiology, Paris, 98(4-6), pp. 357-373.

Weiskopf, N. (2012) 'Real-time fMRI and its application to neurofeedback', Neurolmage, 62(2), pp. 682-692.

Weiss, F. et al. (2020) 'Just a very expensive breathing training? Risk of respiratory artefacts in functional connectivity-based real-time fMRI neurofeedback', Neurolmage, 210, p. 116580.

Whitfield-Gabrieli, S. and Ford, J. M. (2012) 'Default mode network activity and connectivity in psychopathology', Annual review of clinical psychology, 8, pp. 49-76.

Woo, C.-W. et al. (2017) 'Quantifying cerebral contributions to pain beyond nociception', Nature communications, 8, p. 14211. 
Yamashita, A. et al. (2017) 'Connectivity Neurofeedback Training Can Differentially Change Functional Connectivity and Cognitive Performance', Cerebral cortex , 27(10), pp. 4960-4970.

Yao, S. et al. (2016) 'Voluntary control of anterior insula and its functional connections is feedback-independent and increases pain empathy', Neurolmage, 130, pp. 230-240.

Yoo, S.-S. et al. (2004) 'Brain-computer interface using fMRI: spatial navigation by thoughts', Neuroreport, 15(10), p. 1591.

Yoo, S.-S. and Jolesz, F. A. (2002) 'Functional MRI for neurofeedback: feasibility study on a hand motor task', Neuroreport, 13(11), pp. 1377-1381.

Young, K. D. et al. (2014) 'Real-time FMRI neurofeedback training of amygdala activity in patients with major depressive disorder', PloS one, 9(2), p. e88785.

Young, K. D., Siegle, G. J., et al. (2017) 'Randomized Clinical Trial of Real-Time fMRI Amygdala Neurofeedback for Major Depressive Disorder: Effects on Symptoms and Autobiographical Memory Recall', The American journal of psychiatry, 174(8), pp. 748-755.

Young, K. D., Misaki, M., et al. (2017) 'Real-Time Functional Magnetic Resonance Imaging Amygdala Neurofeedback Changes Positive Information Processing in Major Depressive Disorder', Biological psychiatry, 82(8), pp. 578-586.

Yuan, H. et al. (2014) 'Resting-state functional connectivity modulation and sustained changes after real-time functional magnetic resonance imaging neurofeedback training in depression', Brain connectivity, 4(9), pp. 690-701.

Zaehringer, J. et al. (2019) 'Improved emotion regulation after neurofeedback: A single-arm trial in patients with borderline personality disorder', Neurolmage. Clinical, 24, p. 102032.

Zhang, S. et al. (2020) 'Pain Control by Co-adaptive Learning in a Brain-Machine Interface', Current biology: CB, 30(20), pp. 3935-3944.e7.

Zhao, Z. et al. (2019) 'Real-Time Functional Connectivity-Informed Neurofeedback of Amygdala-Frontal Pathways Reduces Anxiety', Psychotherapy and psychosomatics, 88(1), pp. 5-15.

Zhou, F. et al. (2020) 'Beyond fear centers - a distributed fMRI-based neuromarker for the subjective experience of fear’, bioRxiv. doi: 10.1101/2020.11.23.394973.

Zilverstand, A. et al. (2015) 'fMRI neurofeedback facilitates anxiety regulation in females with spider phobia', Frontiers in behavioral neuroscience, 9, p. 148.

Zilverstand, A. et al. (2017) 'fMRI Neurofeedback Training for Increasing Anterior Cingulate Cortex Activation in Adult Attention Deficit Hyperactivity Disorder. An Exploratory Randomized, Single-Blinded Study', PloS one, 12(1), p. e0170795.

Zotev, V. et al. (2016) 'Correlation between amygdala BOLD activity and frontal EEG asymmetry during real-time fMRI neurofeedback training in patients with depression', Neurolmage. Clinical, 11, pp. 224-238.

Zotev, V. et al. (2018) 'Real-time fMRI neurofeedback training of the amygdala activity with 
simultaneous EEG in veterans with combat-related PTSD', Neurolmage. Clinical, 19, pp. 106-121.

Zotev, V. et al. (2020) 'Emotion self-regulation training in major depressive disorder using simultaneous real-time fMRI and EEG neurofeedback', Neurolmage. Clinical, 27, p. 102331.

Zweerings, J. et al. (2019) 'Neurofeedback of core language network nodes modulates connectivity with the default-mode network: A double-blind fMRI neurofeedback study on auditory verbal hallucinations', Neurolmage, 189, pp. 533-542. 
Table 1. Controlled and blinded studies using fMRI neurofeedback in mental health.

\begin{tabular}{|c|c|c|c|c|c|c|c|c|c|c|c|c|}
\hline Disorder & Study & Population & $\mathbf{N}$ & Brain target & Control & $\begin{array}{c}\text { Single I } \\
\text { double-blind }\end{array}$ & $\begin{array}{c}\text { Random } \\
\text {-ization }\end{array}$ & $\begin{array}{l}\text { Explicit } \\
\text { strategy }\end{array}$ & $\begin{array}{c}\text { Continuous } \\
\text { I } \\
\text { Intermittent } \\
\text { feedback }\end{array}$ & $\begin{array}{l}\text { Effect } \\
\text { on } \\
\text { brain } \\
\text { target }\end{array}$ & $\begin{array}{l}\text { Effect on } \\
\text { clinically } \\
\text { relevant } \\
\text { outcomes }\end{array}$ & Effect size \\
\hline \multirow[t]{3}{*}{ ADHD } & $\begin{array}{l}\text { (Alegria } \\
\text { et al., } \\
2017 ; \\
\text { Rubia et } \\
\text { al., 2019) }\end{array}$ & $\begin{array}{l}\text { Children } \\
\text { with ADHD }\end{array}$ & $\begin{array}{l}\mathrm{N} \text { active }= \\
18 \\
\mathrm{~N} \text { control } \\
=13\end{array}$ & $\begin{array}{l}\text { Right inferior } \\
\text { frontal gyrus }\end{array}$ & $\begin{array}{l}\text { Active control } \\
\text { group (left middle } \\
\text { parahippocampal } \\
\text { gyrus) }\end{array}$ & Single-blind & Yes & No & Continuous & Yes & $\begin{array}{l}\text { No } \\
\text { between-group } \\
\text { effect on clinical } \\
\text { outcomes, but } \\
\text { some transfert } \\
\text { effects. }\end{array}$ & N/A \\
\hline & $\begin{array}{l}\text { (deBette } \\
\text { ncourt et } \\
\text { al., 2015) }\end{array}$ & $\begin{array}{l}\text { Healthy } \\
\text { individuals }\end{array}$ & $\begin{array}{l}\mathrm{N} \text { active }= \\
16 \\
\mathrm{~N} \text { control } \\
=16\end{array}$ & $\begin{array}{l}\text { Whole-brain } \\
\text { decoder of } \\
\text { task-relevant } \\
\text { object category } \\
\text { (face or scene) }\end{array}$ & $\begin{array}{l}\text { Active control } \\
\text { group, the } \\
\text { no-feedback } \\
\text { behavioral group, } \\
\text { the RT-feedback } \\
\text { behavioral group } \\
\text { and the RT-control } \\
\text { behavioral group }\end{array}$ & Single-blind & No & $\begin{array}{l}\text { Yes. } \\
\text { Instructed } \\
\text { to pay } \\
\text { attention. }\end{array}$ & Continuous & Yes & $\begin{array}{l}\text { Between-group } \\
\text { and } \\
\text { within-group } \\
\text { effects on } \\
\text { sensitivity in a } \\
\text { sustained } \\
\text { attention task }\end{array}$ & $\mathrm{N} / \mathrm{A}$ \\
\hline & $\begin{array}{l}\text { (Zilversta } \\
\text { nd et al., } \\
2017 \text { ) }\end{array}$ & $\begin{array}{l}\text { Adults with } \\
\text { ADHD }\end{array}$ & $\begin{array}{l}\mathrm{N} \text { active }= \\
7 \\
\mathrm{~N} \text { control } \\
=6\end{array}$ & $\begin{array}{l}\text { Dorsal anterior } \\
\text { cingulate cortex }\end{array}$ & $\begin{array}{l}\text { Control cognitive } \\
\text { training }\end{array}$ & Single-blind & Yes & $\begin{array}{l}\text { Yes. } \\
\text { Mental } \\
\text { calculation. }\end{array}$ & Continuous & $\begin{array}{l}\text { Not } \\
\text { different } \\
\text { from the } \\
\text { control } \\
\text { group. }\end{array}$ & $\begin{array}{l}\text { No } \\
\text { between-group } \\
\text { effect on clinical } \\
\text { outcomes, but } \\
\text { some effects on } \\
\text { cognitive } \\
\text { functioning (i.e., } \\
\text { sustained visual } \\
\text { attention and } \\
\text { visual working } \\
\text { memory) }\end{array}$ & $\begin{array}{l}\text { sustained } \\
\text { visual } \\
\text { attention: } \eta \\
\mathrm{p} 2=0.50 \\
\text { visual } \\
\text { working } \\
\text { memory: } \eta \\
\text { p2 }=0.56\end{array}$ \\
\hline \multirow[t]{2}{*}{ Anxiety } & $\begin{array}{l}\text { (Scheino } \\
\text { st et al., } \\
\text { 2013) }\end{array}$ & $\begin{array}{l}\text { Subclinical } \\
\text { population } \\
\text { with high } \\
\text { contaminati } \\
\text { on- } \\
\text { related } \\
\text { anxiety }\end{array}$ & $\begin{array}{l}\mathrm{N} \text { active }= \\
10 \\
\mathrm{~N} \\
\text { control= } \\
10\end{array}$ & $\begin{array}{l}\text { Orbitofrontal } \\
\text { cortex }\end{array}$ & $\begin{array}{l}\text { Sham control } \\
\text { group }\end{array}$ & Single-blind & Yes & No & Continuous & $\begin{array}{l}\text { Yes. } \\
\text { Change } \\
\mathrm{s} \text { in the } \\
\text { function } \\
\text { al } \\
\text { connecti } \\
\text { vity of } \\
\text { the } \\
\text { targeted } \\
\text { region. }\end{array}$ & $\begin{array}{l}\text { Between-group } \\
\text { and } \\
\text { within-group } \\
\text { effects on } \\
\text { reported control } \\
\text { over } \\
\text { contamination } \\
\text { anxiety. }\end{array}$ & N/A \\
\hline & $\begin{array}{l}\text { (Tascher } \\
\text { eau-Dum } \\
\text { ouchel et }\end{array}$ & $\begin{array}{l}\text { Subclinical } \\
\text { population } \\
\text { reporting }\end{array}$ & $N=16$ & $\begin{array}{l}\text { Decoded activity } \\
\text { of the targeted } \\
\text { feared animal in }\end{array}$ & $\begin{array}{l}\text { Within-subject } \\
\text { control condition } \\
\text { (brain decoder of }\end{array}$ & Double-blind & Yes & No & Intermittent & $\begin{array}{l}\text { Yes. } \\
\text { Increas } \\
\text { ed }\end{array}$ & $\begin{array}{l}\text { Between-group } \\
\text { and } \\
\text { within-group }\end{array}$ & $\begin{array}{l}\text { Amygdala } \\
\text { reactivity: } \\
\text { Cohen's d = }\end{array}$ \\
\hline
\end{tabular}




\begin{tabular}{|c|c|c|c|c|c|c|c|c|c|c|c|c|}
\hline & al., 2018) & $\begin{array}{l}\text { high fear of } \\
\text { specific } \\
\text { animals. }\end{array}$ & & $\begin{array}{l}\text { the ventral } \\
\text { temporal cortex. }\end{array}$ & $\begin{array}{l}\text { another feared } \\
\text { animal) }\end{array}$ & & & & & $\begin{array}{l}\text { likelihoo } \\
\mathrm{d} \text { of the } \\
\text { active } \\
\text { conditio } \\
\mathrm{n} \text { during } \\
\text { inductio } \\
\mathrm{n} \text { (with } \\
\text { respect } \\
\text { to } \\
\text { control). }\end{array}$ & $\begin{array}{l}\text { effects on } \\
\text { decreased } \\
\text { amygdala } \\
\text { reactivity and } \\
\text { physiological } \\
\text { defensive } \\
\text { responses. }\end{array}$ & $\begin{array}{l}0.62 \\
\text { Skin } \\
\text { conductance } \\
\text { response: } \\
\text { Cohen's d = } \\
0.55\end{array}$ \\
\hline & $\begin{array}{l}\text { (Zhao et } \\
\text { al., 2019) }\end{array}$ & $\begin{array}{l}\text { Subclinical } \\
\text { population } \\
\text { with high } \\
\text { trait anxiety }\end{array}$ & $N=26$ & $\begin{array}{l}\text { Connectivity } \\
\text { between the } \\
\text { vIPFC and the } \\
\text { amygdala }\end{array}$ & $\begin{array}{l}\text { crossover sham- } \\
\text { controlled design }\end{array}$ & Single-blind & Yes & $\begin{array}{l}\text { Yes. } \\
\text { Emotional } \\
\text { control } \\
\text { strategy. }\end{array}$ & Continuous & $\begin{array}{l}\text { Yes. } \\
\text { Increas } \\
\text { e in } \\
\text { connecti } \\
\text { vity } \\
\text { within } \\
\text { the } \\
\text { active } \\
\text { but not } \\
\text { the } \\
\text { control } \\
\text { pathway }\end{array}$ & $\begin{array}{l}\text { Between-group } \\
\text { and } \\
\text { within-group } \\
\text { effects on } \\
\text { self-reported } \\
\text { anxiety level } \\
\text { (marginally } \\
\text { significant } \\
\text { interaction) }\end{array}$ & $\begin{array}{c}\text { Within-group } \\
\text { effect size = } \\
0.46\end{array}$ \\
\hline & $\begin{array}{l}\text { (Zilversta } \\
\text { nd et al., } \\
2015 \text { ) }\end{array}$ & $\begin{array}{l}\text { Spider } \\
\text { phobia }\end{array}$ & $\begin{array}{l}\mathrm{N} \text { active }= \\
9 \\
\mathrm{~N} \\
\text { control }=9\end{array}$ & $\begin{array}{l}\text { Dual } \\
\text { neurofeedback } \\
\text { (dIPFC and } \\
\text { insula) }\end{array}$ & $\begin{array}{l}\text { No-feedback } \\
\text { control group }\end{array}$ & Single-blind & Yes & $\begin{array}{l}\text { Yes. } \\
\text { Cognitive } \\
\text { reappraisal } \\
\text {. Note that } \\
\text { the control } \\
\text { group was } \\
\text { not } \\
\text { provided } \\
\text { with the } \\
\text { same } \\
\text { strategy. }\end{array}$ & Intermittent & $\begin{array}{l}\text { Yes for } \\
\text { the } \\
\text { Insula. } \\
\text { No for } \\
\text { the } \\
\text { dIPFC. }\end{array}$ & $\begin{array}{l}\text { Between-group } \\
\text { and } \\
\text { within-group } \\
\text { effects on } \\
\text { subjective } \\
\text { anxiety levels } \\
\text { during } \\
\text { exposure. }\end{array}$ & $\eta \mathrm{p} 2=0.34$ \\
\hline $\begin{array}{l}\text { Autism } \\
\text { spectru } \\
\text { m } \\
\text { disorder }\end{array}$ & $\begin{array}{l}\text { (Ramot } \\
\text { et al., } \\
2017 \text { ) }\end{array}$ & $\begin{array}{l}\text { Adults with } \\
\text { Autism } \\
\text { spectrum } \\
\text { disorder }\end{array}$ & $\begin{array}{l}N \text { patients } \\
=19 \\
\mathrm{~N} \text { Healthy } \\
\text { controls = } \\
10\end{array}$ & $\begin{array}{l}\text { two-point } \\
\text { approach (Target } \\
\text { 1: STS; Target 2: } \\
\text { Somatosensory; } \\
\text { Control: IPL) }\end{array}$ & $\begin{array}{l}\text { Active control } \\
\text { group (Healthy } \\
\text { participants) }\end{array}$ & Single-blind & No & No & Continuous & Yes & $\begin{array}{l}\text { Within-subject } \\
\text { association } \\
\text { between the } \\
\text { Social } \\
\text { Responsivenes } \\
\text { s Scale and } \\
\text { changes in } \\
\text { resting-state } \\
\text { connectivity. No } \\
\text { between-group } \\
\text { effect. }\end{array}$ & $\begin{array}{c}\text { Within-group } \\
r=0.56\end{array}$ \\
\hline Major & (Hamilton & Adults with & $\mathrm{N}$ active $=$ & Localizer in & Sham control & Double-blind & No & Yes. & Intermittent & Yes & Between-group & Between-gro \\
\hline
\end{tabular}




\begin{tabular}{|c|c|c|c|c|c|c|c|c|c|c|c|c|}
\hline $\begin{array}{l}\text { Depress } \\
\text { ive } \\
\text { disorder }\end{array}$ & $\begin{array}{l}\text { et al., } \\
\text { 2016) }\end{array}$ & $\begin{array}{l}\text { major } \\
\text { depressive } \\
\text { disorder }\end{array}$ & $\begin{array}{l}10 \\
\mathrm{~N} \text { control } \\
=10\end{array}$ & $\begin{array}{l}\text { dACC and } \\
\text { fronto-insular } \\
\text { cortex }\end{array}$ & group & & & $\begin{array}{l}\text { strategies } \\
\text { involving } \\
\text { cognitive } \\
\text { reappraisal } \\
\text { ' } \\
\text { attentional } \\
\text { redirection, } \\
\text { and } \\
\text { imagery. }\end{array}$ & & & $\begin{array}{l}\text { and } \\
\text { within-group } \\
\text { effects on } \\
\text { decreased } \\
\text { negative } \\
\text { affective bias } \\
\text { and ratings of } \\
\text { self-relevance } \\
\text { of the negative } \\
\text { adjectives }\end{array}$ & $\begin{array}{c}\text { up effect of } \\
\text { decreased } \\
\text { negative } \\
\text { bias: } \\
\text { Cohen's } d= \\
.78 \\
\text { and ratings } \\
\text { of } \\
\text { self-relevanc } \\
\text { e of the } \\
\text { negative } \\
\text { adjective: } \\
\text { Cohen's } d= \\
0.73\end{array}$ \\
\hline & $\begin{array}{l}\text { (Mehler } \\
\text { et al., } \\
2018 \text { ) }\end{array}$ & $\begin{array}{l}\text { Adults with } \\
\text { major } \\
\text { depressive } \\
\text { disorder }\end{array}$ & $\begin{array}{l}\mathrm{N} \text { active }= \\
16 \\
\mathrm{~N} \text { control } \\
=16\end{array}$ & $\begin{array}{l}\text { Localizer in } \\
\text { anterior brain } \\
\text { areas (e.g., } \\
\text { insula and } \\
\text { striatum) }\end{array}$ & $\begin{array}{l}\text { Active control } \\
\text { group (PPA) }\end{array}$ & Single-blind & Yes & $\begin{array}{l}\text { Yes. } \\
\text { Potential } \\
\text { starting } \\
\text { strategies: } \\
\text { the active } \\
\text { group: } \\
\text { imagery of } \\
\text { positive } \\
\text { stimuli. } \\
\text { The control } \\
\text { group: } \\
\text { imagery of } \\
\text { scenes. }\end{array}$ & Continuous & Yes & $\begin{array}{l}\text { No } \\
\text { between-group } \\
\text { effect on clinical } \\
\text { outcomes, but } \\
\text { within-group } \\
\text { effects are } \\
\text { observed. }\end{array}$ & $\begin{array}{l}\text { Within-group } \\
\text { effect of } \mathrm{g}= \\
1.46\end{array}$ \\
\hline & $\begin{array}{l}\text { (Young et } \\
\text { al., 2014; } \\
\text { Yuan et } \\
\text { al., 2014) }\end{array}$ & $\begin{array}{l}\text { Adults with } \\
\text { major } \\
\text { depressive } \\
\text { disorder }\end{array}$ & $\begin{array}{l}\mathrm{N} \text { active }= \\
14 \\
\mathrm{~N} \text { control } \\
=7\end{array}$ & Left amygdala & $\begin{array}{l}\text { Active control } \\
\text { group } \\
\text { (Intraparietal } \\
\text { sulcus) }\end{array}$ & Double-blind & No & $\begin{array}{l}\text { Yes. } \\
\text { Happy } \\
\text { Memories, } \\
\text { Count, and } \\
\text { Rest con- } \\
\text { ditions. }\end{array}$ & Continuous & Yes & $\begin{array}{l}\text { Between-group } \\
\text { effect on mood } \\
\text { scales (VAS } \\
\text { Happiness } \\
\text { ratings, and } \\
\text { STAI state } \\
\text { anxiety) }\end{array}$ & N/A \\
\hline & $\begin{array}{l}\text { (Young, } \\
\text { Siegle, et } \\
\text { al., 2017) }\end{array}$ & $\begin{array}{l}\text { Adults with } \\
\text { major } \\
\text { depressive } \\
\text { disorder }\end{array}$ & $\begin{array}{l}\mathrm{N} \text { active }= \\
19 \\
\mathrm{~N} \text { control } \\
=17\end{array}$ & Left amygdala & $\begin{array}{l}\text { Active control } \\
\text { group } \\
\text { (Intraparietal } \\
\text { sulcus) }\end{array}$ & Double-blind & Yes & $\begin{array}{l}\text { Yes. } \\
\text { Happy } \\
\text { Memories, } \\
\text { Count, and } \\
\text { Rest con- } \\
\text { ditions. }\end{array}$ & Continuous & Yes & $\begin{array}{l}\text { Between-group } \\
\text { effect on } \\
\text { multiple clinical } \\
\text { scores } \\
\text { (MADRS, } \\
\text { BDI-II, and } \\
\text { HAM-D). }\end{array}$ & $\begin{array}{c}\text { Mean } \\
\text { between-gro } \\
\text { up effect on } \\
\text { MADR: } \\
\text { Cohen's d = } \\
1.03 \\
\text { BDI-II: } \\
\text { Cohen's } d= \\
0.73 \\
\text { HAM-D: } \\
\text { Cohen's d = } \\
0.79\end{array}$ \\
\hline
\end{tabular}




\begin{tabular}{|c|c|c|c|c|c|c|c|c|c|c|c|c|}
\hline & $\begin{array}{l}\text { (Zotev et } \\
\text { al., 2016) }\end{array}$ & $\begin{array}{l}\text { Adults with } \\
\text { major } \\
\text { depressive } \\
\text { disorder }\end{array}$ & $\begin{array}{l}\mathrm{N} \text { active }= \\
13 \\
\mathrm{~N} \text { control } \\
=11\end{array}$ & Left amygdala & $\begin{array}{l}\text { Active control } \\
\text { group } \\
\text { (Intraparietal } \\
\text { sulcus) }\end{array}$ & Single-blind & No & $\begin{array}{l}\text { Yes. } \\
\text { Happy } \\
\text { Memories, } \\
\text { Count, and } \\
\text { Rest con- } \\
\text { ditions. }\end{array}$ & Continuous & $\begin{array}{l}\text { Yes. } \\
\text { Group } \\
\text { effect } \\
\text { for the } \\
\text { Happy } \\
\text { vs } \\
\text { Count } \\
\text { contrast } \\
\text {. }\end{array}$ & $\begin{array}{l}\text { Between-group } \\
\text { effect on } \\
\text { emotional state } \\
\text { improvement. }\end{array}$ & $\mathrm{N} / \mathrm{A}$ \\
\hline & $\begin{array}{l}\text { (Mennen } \\
\text { et al., } \\
2021 \text { ) }\end{array}$ & $\begin{array}{l}\text { Adults with } \\
\text { major } \\
\text { depressive } \\
\text { disorder }\end{array}$ & $\begin{array}{l}\text { N patients } \\
=14 \\
\mathrm{~N} \text { Healthy } \\
\text { controls = } \\
12\end{array}$ & $\begin{array}{l}\text { Whole-brain } \\
\text { decoder of } \\
\text { task-relevant } \\
\text { object category } \\
\text { (face or scene) }\end{array}$ & $\begin{array}{l}\text { Active control } \\
\text { Group (Healthy } \\
\text { individuals) }\end{array}$ & Single-blind & No & $\begin{array}{l}\text { Yes. } \\
\text { Informed } \\
\text { informed } \\
\text { that the } \\
\text { change in } \\
\text { opacity } \\
\text { was } \\
\text { determined } \\
\text { by their } \\
\text { brain ac- } \\
\text { tivity. }\end{array}$ & Continuous & Yes & $\begin{array}{l}\text { Between-group } \\
\text { and } \\
\text { within-group } \\
\text { effects on the } \\
\text { probability to } \\
\text { get stuck in the } \\
\text { most negative } \\
\text { State (negative } \\
\text { faces). }\end{array}$ & $\mathrm{N} / \mathrm{A}$ \\
\hline \multirow[t]{2}{*}{$\begin{array}{l}\text { Post-tra } \\
\text { umatic } \\
\text { stress } \\
\text { disorder }\end{array}$} & $\begin{array}{l}\text { (Keynan } \\
\text { et al., } \\
2019 \text { ) }\end{array}$ & $\begin{array}{l}\text { Healthy } \\
\text { man going } \\
\text { through } \\
\text { military } \\
\text { training }\end{array}$ & $\begin{array}{l}\mathrm{N} \text { active }= \\
90 \\
\mathrm{~N} \text { control } \\
=45 \\
\mathrm{~N} \text { no } \\
\text { feedback } \\
\text { control = } \\
45\end{array}$ & $\begin{array}{l}\text { EEG-fingerprint } \\
\text { of the amygdala }\end{array}$ & $\begin{array}{l}\text { Active control } \\
\text { group } \\
\text { (Alpha-Theta } \\
\text { training) } \\
\text { No feedback } \\
\text { group }\end{array}$ & Double-blind & Yes & No & Continuous & Yes & $\begin{array}{l}\text { Between-group } \\
\text { and } \\
\text { within-group } \\
\text { effects on } \\
\text { emotion } \\
\text { regulation } \\
\text { (emotional } \\
\text { stroop and } \\
\text { alexithymia } \\
\text { questionnaire) }\end{array}$ & 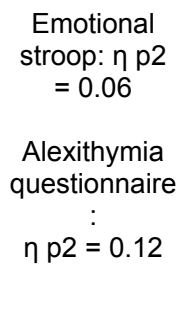 \\
\hline & $\begin{array}{l}\text { (Misaki et } \\
\text { al., 2018; } \\
\text { Zotev et } \\
\text { al., 2018) }\end{array}$ & $\begin{array}{l}\text { Veterans } \\
\text { with } \\
\text { combat-rela } \\
\text { ted PTSD }\end{array}$ & $\begin{array}{l}\mathrm{N} \text { active }= \\
20 \\
\mathrm{~N} \text { control } \\
=11\end{array}$ & Left amygdala & $\begin{array}{l}\text { Active control } \\
\text { group } \\
\text { (Intraparietal } \\
\text { sulcus) }\end{array}$ & Single-blind & Yes & $\begin{array}{l}\text { Yes. } \\
\text { Happy } \\
\text { Memories, } \\
\text { Count, and } \\
\text { Rest con- } \\
\text { ditions. }\end{array}$ & Continuous & $\begin{array}{l}\text { Not a } \\
\text { clear } \\
\text { learning } \\
\text { effect. }\end{array}$ & $\begin{array}{l}\text { No } \\
\text { between-group } \\
\text { effect. } \\
\text { Within-group } \\
\text { effect on CAPS } \\
\text { scores. }\end{array}$ & $\mathrm{N} / \mathrm{A}$ \\
\hline $\begin{array}{l}\text { Schizop } \\
\text { hrenia }\end{array}$ & $\begin{array}{l}\text { (Bauer et } \\
\text { al., 2020) }\end{array}$ & $\begin{array}{l}\text { Schizophre } \\
\text { nia or }\end{array}$ & $N=11$ & $\begin{array}{l}\text { Central } \\
\text { Executive }\end{array}$ & $\begin{array}{l}\text { Active control } \\
\text { condition }\end{array}$ & Single-blind & No & $\begin{array}{l}\text { Yes. } \\
\text { Meditation }\end{array}$ & Continuous & $\begin{array}{l}\text { Not } \\
\text { availabl }\end{array}$ & $\begin{array}{l}\text { Effect reported } \\
\text { on auditory }\end{array}$ & $\begin{array}{l}\text { Active } \\
\text { condition: }\end{array}$ \\
\hline
\end{tabular}




\begin{tabular}{|c|c|c|c|c|c|c|c|c|c|c|c|c|}
\hline & & $\begin{array}{l}\text { schizoaffect } \\
\text { ive disorder }\end{array}$ & & $\begin{array}{l}\text { Network minus } \\
\text { the default mode } \\
\text { network }\end{array}$ & (crossover design) & & & $\begin{array}{l}\text { (Mental } \\
\text { noting) }\end{array}$ & & e & $\begin{array}{l}\text { hallucinations } \\
\text { following the } \\
\text { active condition. } \\
\text { No direct } \\
\text { comparison with } \\
\text { the control } \\
\text { condition. }\end{array}$ & $\begin{array}{c}\text { Cohen's d = } \\
0.57\end{array}$ \\
\hline & $\begin{array}{l}\text { (Okano } \\
\text { et al., } \\
2020 \text { ) }\end{array}$ & $\begin{array}{l}\text { Schizophre } \\
\text { nia or } \\
\text { schizoaffect } \\
\text { ive disorder }\end{array}$ & $N=10$ & $\begin{array}{l}\text { Superior } \\
\text { temporal gyrus }\end{array}$ & $\begin{array}{l}\text { Active control } \\
\text { condition } \\
\text { (crossover design) }\end{array}$ & Single-blind & No & $\begin{array}{l}\text { Yes. Listen } \\
\text { or ignore } \\
\text { spoken } \\
\text { sentences. }\end{array}$ & Intermittent & $\begin{array}{l}\text { Effect } \\
\text { reported } \\
\text { in the } \\
\text { active } \\
\text { group. } \\
\text { No test } \\
\text { reportin } \\
\text { g the } \\
\text { interacti } \\
\text { on. }\end{array}$ & $\begin{array}{l}\text { Effect reported } \\
\text { on auditory } \\
\text { hallucinations } \\
\text { following the } \\
\text { active condition. } \\
\text { No direct } \\
\text { comparison with } \\
\text { the control } \\
\text { condition. }\end{array}$ & $\mathrm{N} / \mathrm{A}$ \\
\hline & $\begin{array}{l}\text { (Zweerin } \\
\text { gs et al., } \\
\text { 2019) }\end{array}$ & $\begin{array}{l}\text { Adults with } \\
\text { schzophren } \\
\text { ia }\end{array}$ & $\begin{array}{l}\text { N patients } \\
=21 \\
\mathrm{~N} \text { Healthy } \\
\text { controls = } \\
35\end{array}$ & $\begin{array}{l}\text { Inferior frontal } \\
\text { gyrus and } \\
\text { posterior } \\
\text { superior temporal } \\
\text { gyrus }\end{array}$ & $\begin{array}{l}\text { Randomized } \\
\text { cross-over design } \\
\text { (up- regulate and } \\
\text { down-regulate) } \\
\text { with active control } \\
\text { group }\end{array}$ & Double-blind & $\begin{array}{l}\text { Yes. } \\
\text { Conditio } \\
\text { n order. }\end{array}$ & $\begin{array}{l}\text { Yes. (1) } \\
\text { recalling } \\
\text { positive } \\
\text { autobio- } \\
\text { graphic } \\
\text { memories, } \\
(2) \\
\text { imagining } \\
\text { spoken } \\
\text { language } \\
\text { or (3) } \\
\text { imagining } \\
\text { a } \\
\text { relaxing } \\
\text { situation }\end{array}$ & Intermittent & $\begin{array}{l}\text { Within-g } \\
\text { roup. } \\
\text { No } \\
\text { betwee } \\
\text { n-group } \\
\text { effect. }\end{array}$ & $\begin{array}{l}\text { No } \\
\text { between-group } \\
\text { effect. } \\
\text { Within-group } \\
\text { association } \\
\text { between the } \\
\text { change in } \\
\text { functional } \\
\text { connectivity and } \\
\text { the change in } \\
\text { the global } \\
\text { severity index. }\end{array}$ & $\mathrm{N} / \mathrm{A}$ \\
\hline $\begin{array}{l}\text { Substan } \\
\text { ce } \\
\text { abuse }\end{array}$ & $\begin{array}{l}\text { (Hartwell } \\
\text { et al., } \\
2016)\end{array}$ & $\begin{array}{l}\text { Nicotine-de } \\
\text { pendent } \\
\text { smokers }\end{array}$ & $\begin{array}{l}\mathrm{N} \text { active }= \\
21 \\
\mathrm{~N} \text { control } \\
=23\end{array}$ & $\begin{array}{l}\text { Anterior cingulate } \\
\text { cortex and } \\
\text { orbitofrontal } \\
\text { cortex }\end{array}$ & $\begin{array}{l}\text { No feedback } \\
\text { control group }\end{array}$ & Single-blind & Yes & $\begin{array}{l}\text { Yes. } \\
\text { Reduce } \\
\text { craving } \\
\text { during cue } \\
\text { exposure. }\end{array}$ & Intermittent & Yes & $\begin{array}{l}\text { Between-group } \\
\text { effect on the } \\
\text { Questionnaire } \\
\text { of Smoking } \\
\text { Urges (Factor } \\
\text { 1) }\end{array}$ & $\mathrm{N} / \mathrm{A}$ \\
\hline
\end{tabular}




\begin{tabular}{|l|l|l|l|l|l|l|l|l|l|l|}
\hline & & $\begin{array}{l}\text { bilateral posterior } \\
\text { cingulate cortex } \\
\text { and } \\
\text { precuneus areas. }\end{array}$ & & & provided. & & $\begin{array}{l}\text { on craving } \\
\text { scores. }\end{array}$ & \\
\hline
\end{tabular}

If not directly mentioned in the text, single-blind was inferred when patients were unaware of group membership or of experimental conditions (in within-subject designs). Single-blind was not automatically inferred when a healthy control group was used. Double-blind was never inferred and needed to be explicitly stated in the manuscript. 


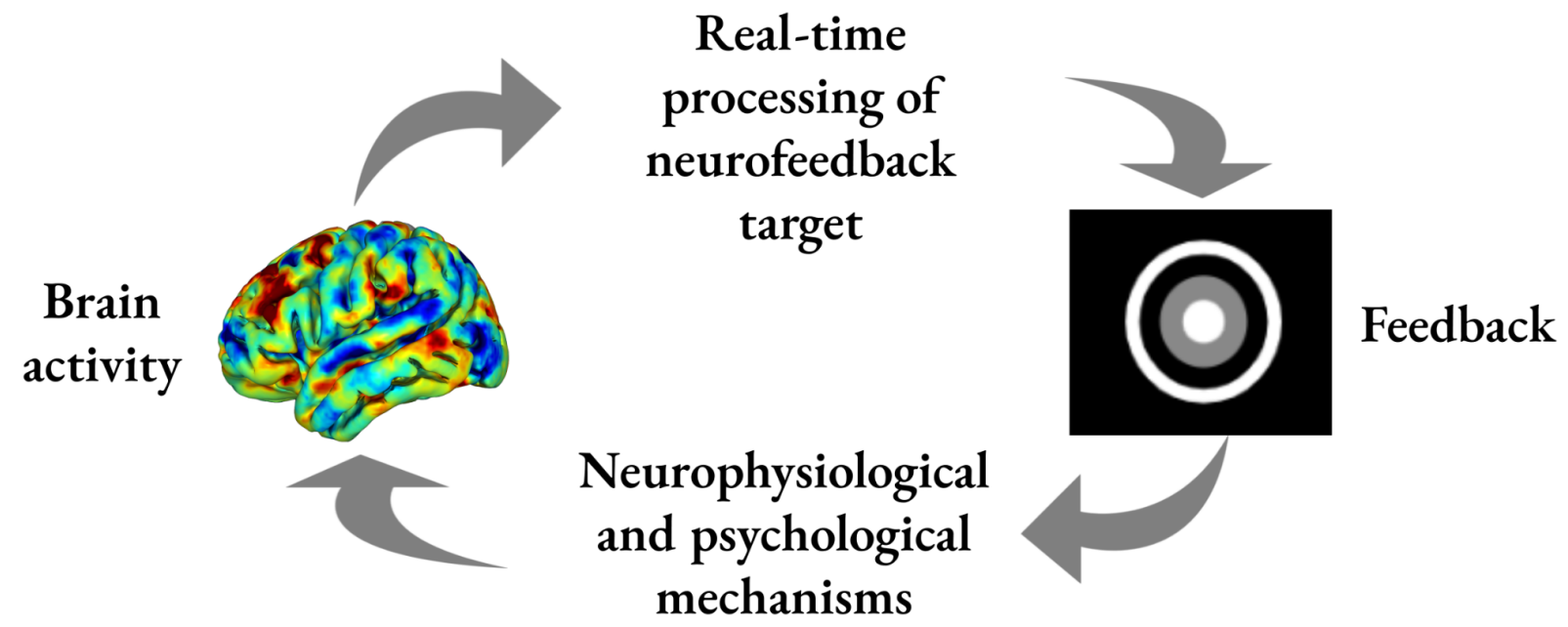

Figure 1. Principle of closed-loop neurofeedback interventions. In closed-loop experiments, a neurofeedback target is processed in real time and fed back to the participant, often in the visual modality. For instance, previous experiments represented the decoded brain activity through the diameter of a circle (right). This feedback process is thought to trigger neurophysiological and psychological mechanisms, possibly related to reinforcement learning, that can over time lead to an increased expression of the targeted brain activity. 


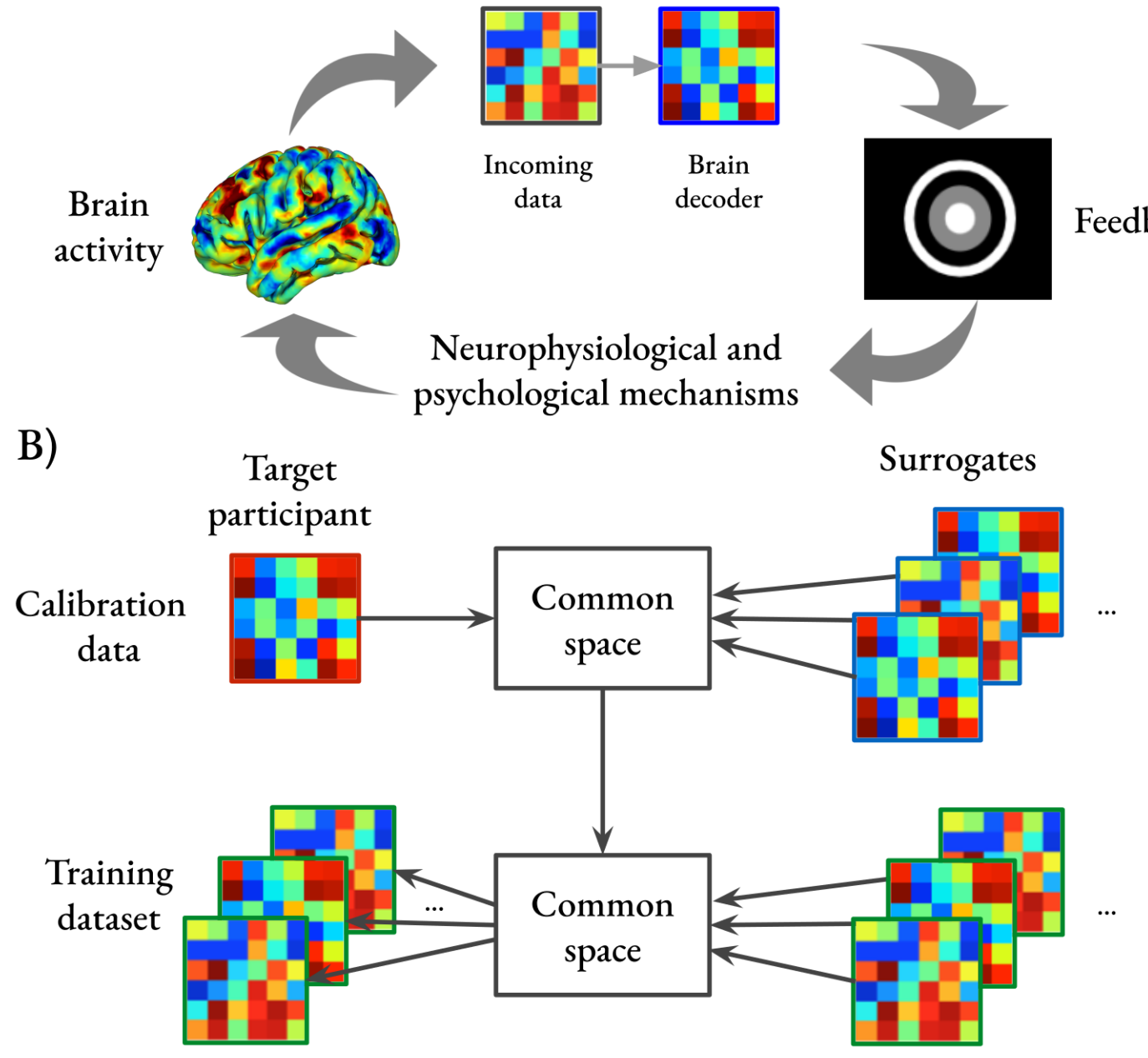

Figure 2 A) Schematic representations of decoded fMRI neurofeedback and B) principle of Hyperalignment. A) Brain activity is pre-processed in real time (i.e., incoming data) and decoded using a pre-trained brain decoder of a specific psychological state. For instance, such a brain decoder can be trained to predict attention to a specific stimulus or the visual presentation of a feared animal. The output of such decoders can for instance indicate how closely the brain activity matches the one of the targeted representations (e.g., activation likelihood). This information is then displayed visually in real time and paired with a monetary reward. This is achieved in order to mobilise neurophysiological and psychological mechanisms facilitating the expression of the targeted brain representation. It could also associate the brain representation with a reward. B) Using Hyperalignment it is possible to represent the brain data of different participants in a common space. The common space is determined by functionally aligning the responses of a group of voxels. This is achieved by presenting participants with a task expected to generate similar response profiles across participants. For instance, the presentation of a movie is expected to generate similar response profiles in the visual system. Once the common space is determined, it is then possible to transform data from the native space of participants to the common space. Importantly, it is also possible to reverse that transformation and to bring data from the common space to the native space of a specific participant. This can notably be achieved for the purpose of neurofeedback training (bottom). 

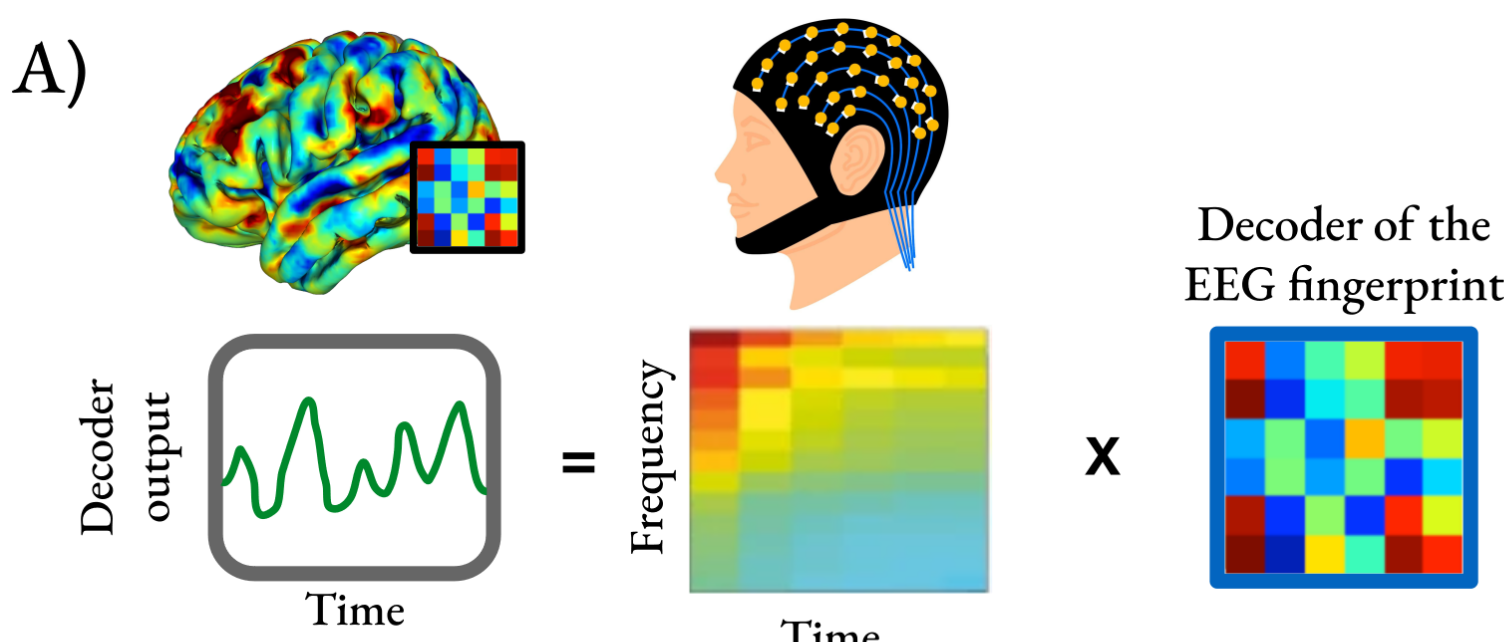

Decoder of the EEG fingerprint

Time

B)
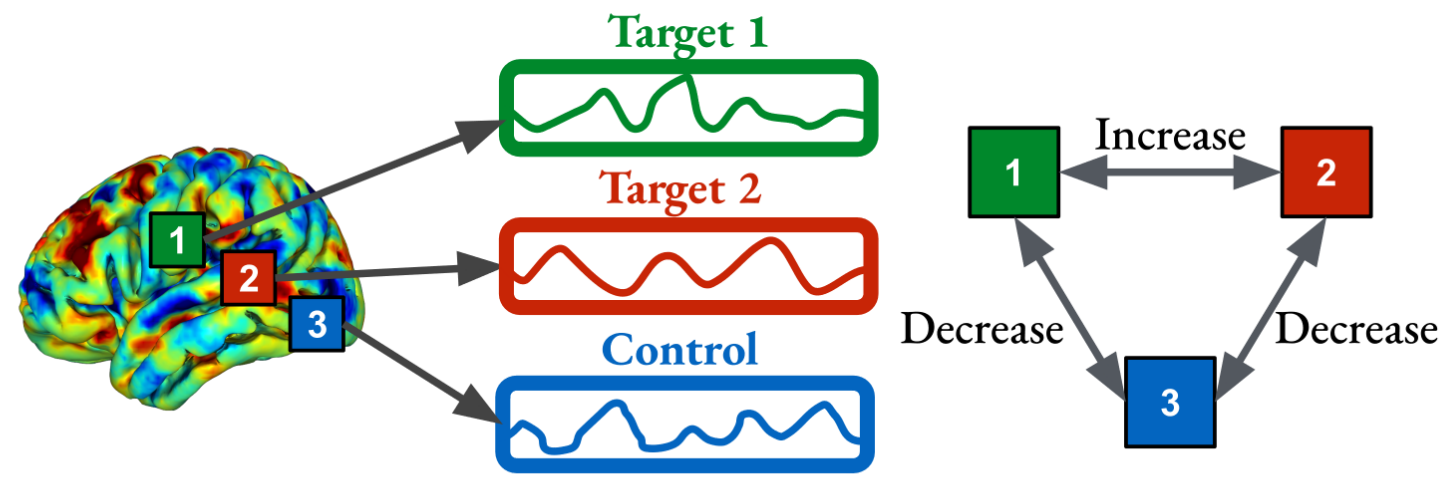

Time

Figure 3. A) Decoding an EEG fingerprint and B) principle of connectivity-based neurofeedback. A) When EEG and fMRI signals are acquired simultaneously, it is possible to train a decoder of EEG activity (i.e., "Decoder of the EEG fingerprint") to predict the fMRI activity. This decoder can later be used outside of the fMRI scanner for neurofeedback purposes. B) Connectivity neurofeedback is conducted in order to reinforce the connectivity between two brain regions (e.g., target 1 and 2). Multiple strategies were used for the purpose of connectivity neurofeedback. An interesting approach involves training participants to increase the connectivity between two target regions while decreasing the connectivity between the targets and a control region (see (Ramot et al., 2017)) 
A)
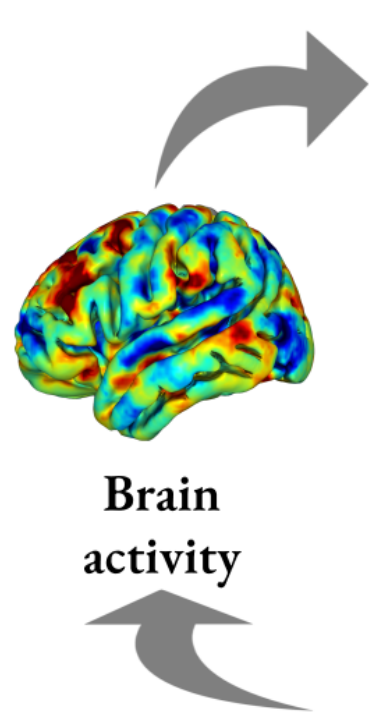

B)

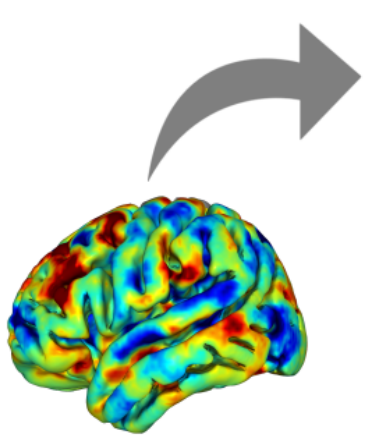

Brain activity

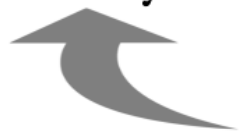

Real-time decoding

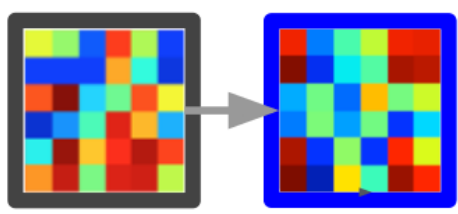

Brain

Incoming data decoder
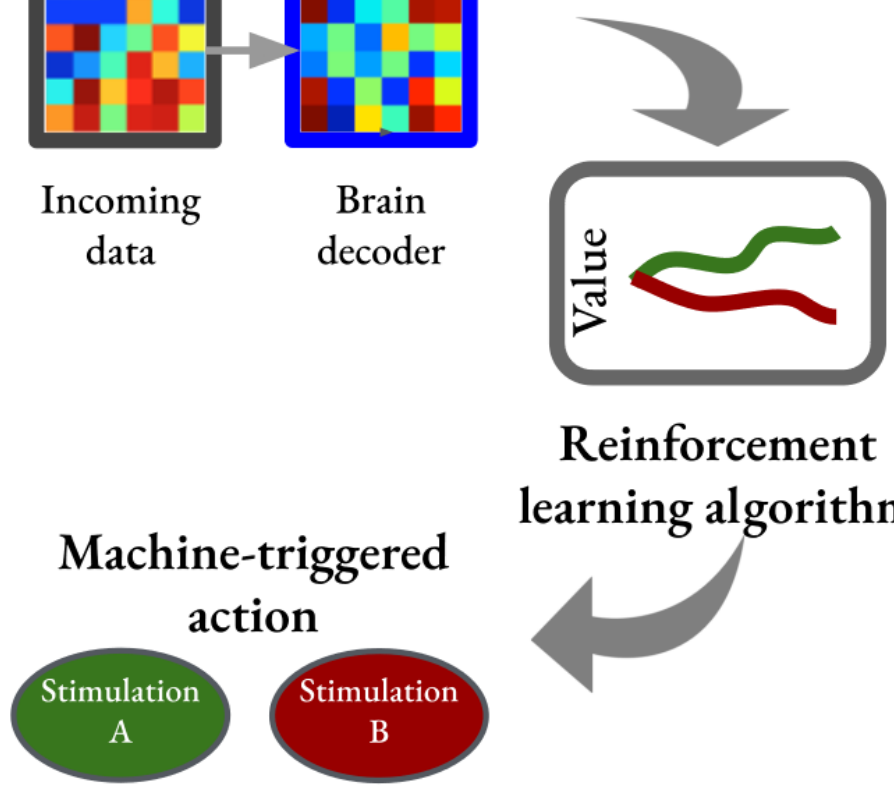

\section{Reinforcement}
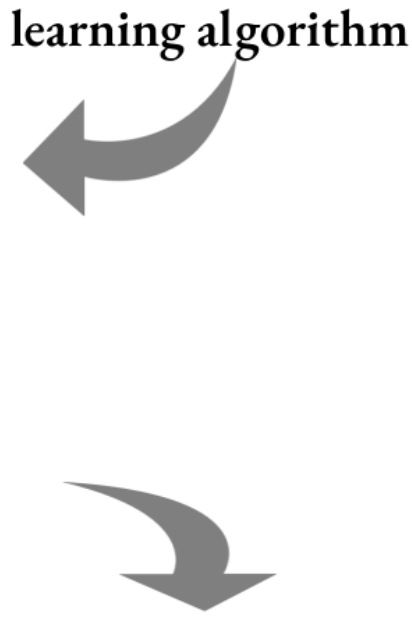

$\underset{\text { data }}{\text { Incoming }}$

Brain

decoder

\section{Stimulus generated to optimise the decoder output}

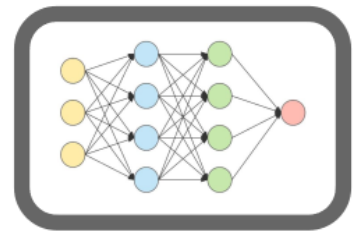
Deep generative model
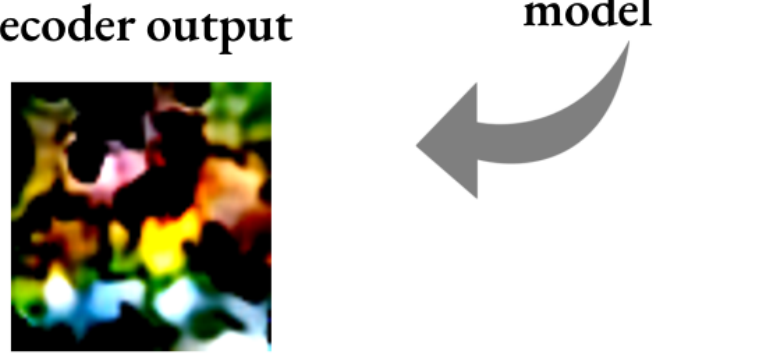

Figure 4 The principle of co-adaptive systems. A) Decoded brain activity can be used in order to train a reinforcement learning model to interact with the user. As described in the main text, an algorithm can learn to interact with the user in order to optimise or minimise the decoded brain activity. B) Similarly, a deep generative model can be used to generate visual stimuli that will optimise or minimise decoded brain activity (Adapted from (Taschereau-Dumouchel and Roy, 2020). 